\title{
Pomegranate: Nutraceutical with Promising Benefits on Human Health
}

\author{
Anna Caruso ${ }^{1,+}$, Alexia Barbarossa ${ }^{2,+}$, Antonio Tassone ${ }^{1}$, Jessica Ceramella ${ }^{1}$, Alessia Carocci ${ }^{2, *}$ (D), \\ Alessia Catalano $^{2}{ }^{\mathbb{D}}$, Giovanna Basile ${ }^{1}$, Alessia Fazio ${ }^{1}$, Domenico Iacopetta ${ }^{1}{ }^{\mathbb{D}}$, Carlo Franchini ${ }^{2}$ \\ and Maria Stefania Sinicropi ${ }^{1}$ (D) \\ 1 Department of Pharmacy, Health and Nutritional Sciences, University of Calabria, 87036 Arcavacata di Rende, \\ Italy; anna.caruso@unical.it (A.C.); antonio.tassone1986@libero.it (A.T.); jessicaceramella@gmail.com (J.C.); \\ biologanutrizionistagb@gmail.com (G.B.); alessia.fazio@unical.it (A.F.); domenico.iacopetta@unical.it (D.I.); \\ s.sinicropi@unical.it (M.S.S.) \\ 2 Department of Pharmacy-Drug Sciences, University of Bari Aldo Moro, 70126 Bari, Italy; \\ alexia.barbarossa@uniba.it (A.B.); alessia.catalano@uniba.it (A.C.); carlo.franchini@uniba.it (C.F.) \\ * Correspondence: alessia.carocci@uniba.it \\ $\dagger$ These authors equally contributed to this work.
}

Received: 9 September 2020; Accepted: 29 September 2020; Published: 2 October 2020

\begin{abstract}
Pomegranate is an old plant made up by flowers, roots, fruits and leaves, native to Central Asia and principally cultivated in the Mediterranean and California (although now widespread almost all over the globe). The current use of this precious plant regards not only the exteriority of the fruit (employed also for ornamental purpose) but especially the nutritional and, still potential, health benefits that come out from the various parts composing this one (carpellary membranes, arils, seeds and bark). Indeed, the phytochemical composition of the fruit abounds in compounds (flavonoids, ellagitannins, proanthocyanidins, mineral salts, vitamins, lipids, organic acids) presenting a significant biological and nutraceutical value. For these reasons, pomegranate interest is increased over the years as the object of study for many research groups, particularly in the pharmaceutical sector. Specifically, in-depth studies of its biological and functional properties and the research of new formulations could be applied to a wide spectrum of diseases including neoplastic, cardiovascular, viral, inflammatory, metabolic, microbial, intestinal, reproductive and skin diseases. In this review, considering the increasing scientific and commercial interest of nutraceuticals, we reported an update of the investigations concerning the health-promoting properties of pomegranate and its bioactive compounds against principal human pathologies.
\end{abstract}

Keywords: pomegranate; Punica granatum L.; pomegranate skin extract; pomegranate fruit extract; nutraceutical properties; biological properties

\section{Introduction}

In the last few years, interest in pomegranate (Punica granatum L. Punicaceae) has risen, because of the nutritional and medical benefits, the external appearance of the fruit, and also for cosmetic and pharmaceutical purposes [1].

Among the varieties known to date, the five most popular in the world are: Wonderful, of American origin; Hicanzar, of Turkish origin; Acco, of Israeli origin; Bagua, of Indian origin; and Mollar de Elche and Valenciana, of Spanish origin [2]. Moreover, there is a dwarf variety of pomegranate, called Punica granatum Nana, characterized by a smaller size and inedible fruits, which is usually used as a small decorative pot plant [3]. Thanks to its different potential health properties, several components of the pomegranate plant, such as fruits, bark, flowers, roots, and leaves, have been employed for medicinal uses for a wide range of pathologies and health disorders [4]. 
The chemical composition of the fruit can vary and depends, above all, on the cultivation area, climate, ripeness, cultivation practices, and storage conditions [4]. The pomegranate is a source of numerous chemical compounds of high biological and nutraceutical value (e.g., phenolic acids, tannins, vitamins, antioxidants, and lipids), that are present in skin, carpellary membranes, arils, and seeds. The most important product derived from it is the juice derived from the arils or the whole fruit [5].

About $50 \%$ of the total weight of the pomegranate is made up of the skin and skin membranes that represent a significant source of flavonoids, ellagitannins, proanthocyanidins, mineral salts as potassium, phosphorus, sodium, magnesium, and iron. On the other hand, the grains are made up of water $(85 \%)$, sugars $(10 \%)$, particularly fructose and glucose, vitamins (including C, A, and group B vitamins), antioxidant substances, organic acids, as ascorbic, citric and malic acid, lipids. The seeds contain fatty acids, whose content ranges from 12 to $20 \%$ of the total weight (dry weight). Amongst them, a higher presence of alpha-linolenic acid (omega 3), linoleic acid (omega 6), and oleic acid (omega 9) has been detected, together with stearic acid, which may lower cholesterol levels, and palmitic acid [6]. Seeds are rich in protein, crude fiber, vitamins, minerals, pectins, sugars, polyphenols, isoflavones (especially genistein), coumestrol, sex steroids as estrone [5].

Today, the nutraceutical properties of the pomegranate arouse considerable interest in the scientific community and literature data reported several studies in which functional activities of the pomegranate and its derivatives, such as juice, seed oil, peel, etc., are highlighted [7]. This review gives an insight to the update of the present knowledge of the potential health benefits of pomegranate.

\section{Pomegranate Health-Promoting Properties}

\subsection{Antioxidant Activity}

Reactive oxygen species (ROS), formed in normal cellular metabolic processes or generated from exposure to ionizing or xenobiotic radiation, are held concausal factors in a large amount of chronic diseases. The toxicity of ROS is attributable to the ability of damaging essential biological substrates, such as DNA, RNA, proteins, and membrane lipids. ROS comprise superoxide radicals, lipoperoxide oxides, hydrogen peroxide, and hydroxyl free radicals [8]. An antioxidant is generally defined as a natural (fruit and vegetables) or artificial substance that can neutralize or protect a biological system from free radicals, such as oxygen, nitrogen, and lipid radicals $[9,10]$. These antioxidant properties make fruit and vegetables elements with good health properties, avoiding or decreasing the risk of suffering from determined degenerative diseases [11-18].

Anthocyanins, phenols [19], and vitamins as A (14), C (15), and E (16) [20] confer the high antioxidant power to pomegranate as reported by several authors in both in vitro and in vivo models [21].

Some authors [22] state that the antioxidant capacity of phenolic compounds is a consequence of their ability to capture free radicals and their chelating ability of metal cations.

Gil et al. [23] reported that the antioxidant effect possessed by pomegranate juice is 3 times higher than that of red wine or green tea and 2, 6, and 8 times superior than that found in red berries, grapefruit, and orange juice, respectively.

In 2013, a parallelism of total phenolic content and antioxidant properties between several extraction solvents of pomegranate seed (PS) and pomegranate defatted seed (PDS) was carried out. Data revealed this trend, in decreasing order, for the used solvents regarding the radical scavenging activity methanol $>$ water $>$ acetone $>$ butanol $>$ ethyl acetate $>$ hexane $\left(E C_{50}\right.$ antiradical potential amounting to 0.14 for PS and $0.19 \mu \mathrm{g} / \mathrm{g}$ for PDS). Similarly, the reducing activity test, decreed that methanol extract of PS an PDS possessed the greater reducing strength [24]. 
Derakhshan et al. in 2018 investigated the antioxidant activity and the total phenolic content of pomegranate peels, juice, and seeds from three regions of Natanz, Shahreza, and Doorak using as solvent ethanol. The best antioxidant activity was obtained by Doorak's seed and peel, as well as for the higher total phenolic content [25].

More recently, the analysis of five pomegranate juices genotypes (Mollar, Kingdom, Dente di Cavallo, and two old populations Francofonte and Santa Tecla) assessed that the total phenolic content ranged between $741.9 \pm 55.8$ and $424.2 \pm 47.5 \mathrm{mg} \mathrm{GAE} / 100 \mathrm{~mL}$ and the Francoforte genotype exhibited the higher amount. Furthermore, twenty-three phenolic compounds were detected. In particular, cyanidin-3,5-O-diglucoside and pelargonidin-3,5-O-diglucoside were the kind of anthocyanins present in all genotypes; the Santa Tecla population possessed the richest amount of these anthocyanins with values of 97.64 and $40.29 \mathrm{mgL}^{-1}$, respectively, whereas in the Francoforte population, ferulic acid hexoside was the most abundant compound $\left(391.18 \mathrm{mgL}^{-1}\right)$. The antioxidant activity values ranged between 221.5 and $36.73 \mu \mathrm{mol}$ Trolox equivalents/100mL of juice and the higher one was observed for the Santa Tecla pomegranate population [26].

Preliminary studies performed by Bernabucci et al. explored the possible beneficial properties of pomegranate peel extracts (PPE) on bovine mammary epithelial cells BME-UV1. Their outcomes evidenced the ability of peel extract to decrease ROS production and malondialdehyde induced by the presence of hydrogen peroxide or lipopolysaccharide. Furthermore, PPE lowered pro-inflammatory cytokines expressions, exhibiting an anti-inflammatory effect on BME-UV1 treated with lipopolysaccharide [27].

A new and interesting study conducted by Hanani et al. addressed this issue from another perspective. Indeed, pomegranate peel powder was integrated into fish gelatin film-forming solution (FFS) with the aim to create an active packaging film. They found that the addition of $1 \%$ of pomegranate peel powder significantly increased the DPPH radical-scavenging activity to $59.74 \%$, whereas the addition of $5 \%$ led to a percentage of $71.82 \%$, and the fish gelatin film without pomegranate peel powder used as control achieved only the $53 \%$ [28].

Similarly, Bertolo et al. aimed to incorporate PPE at different doses to chitosan/gelatin gels. As a consequence, the antioxidant activity of the generated mixture was significantly improved. Moreover, concerning the rheological properties, PPE extended linear viscoelastic range and enabled the samples to easily flow under the applied shear rate boosting, in this way, the functional characteristics of chitosan/gelatin-based materials were improved [29]. In agreement with all these studies are the findings reported by Jalal et al., whose intention was to compare antioxidant activity of pomegranate peel and seed powder extracts through both DPPH and ABTS methods. The two assays evidenced the higher antioxidant capacity in peel powder samples with respect to seed powder samples. Furthermore, the methanolic extracts achieved the best results compared to water extract [30].

Surek et al. analyzed and compared the antioxidant activities of co-products from industrial pasteurized pomegranate nectar (PN), processing the peel (PP), press cake (PC), and precipitate after clarification (PAC) in comparison with raw material (arils) and final products (CON and PN) using DPPH, CUPRAC (Cupric ion reducing antioxidant capacity), FRAP (Ferric Antioxidant Power), and ABTS (2,2'-azino-bis(3-ethylbenzothiazoline-6-sulfonic acid)) methods. PP has shown to possess the greater antioxidant capacity in all the assays. This effect could be due to the presence of a rich amount of phenols, flavonoids, and tannins, compared with the other tested extracts. Consequently, it is plausible to think that discarding the peel would cause a decrease of antioxidant potential [31].

In 2019, deeper analyses were conducted on the principal antioxidants enzymes (peroxisomal catalase and superoxide dismutase (SOD) isozymes) and the NADPH-regenerating system of pomegranate and their possibility to vary for different cultivar and genotypes. In the reported study, there were analyzed seeds and juices from two pomegranate varieties (Valenciana and Mollar) grown in two diverse Spanish locations. The evaluations of the isoenzymatic superoxide dismutase (SOD) activity pattern showed one Mn-SOD and five CuZn-SODs (I-V) whose richness depended on the variety while immunoblot assays exhibited at least one additional Fe-SOD with a subunit size of 
about $23 \mathrm{kDa}$ in both varieties. Moreover, a strong metabolism of ROS could be due to the presence of the $\mathrm{H}_{2} \mathrm{O}_{2}$-scavenging peroxisomal catalase in seeds and juice [32].

The research works mentioned in this section have proven that the major factor responsible for pomegranate antioxidant activity is the presence of polyphenols and anthocyanins. In particular, it has been demonstrated that peel extract is the richest of these elements, which makes it suitable as a natural source of anti-free radicals.

\subsection{Anticancer Properties}

Cancer is the principal cause of death in both developed and developing countries. The mortality rate of this pathology is superior among low and middle-income populations. The higher mortality rates in less well-off countries are mainly due to the lack of adequate health systems [33-36]. Reactive oxygen species' (ROS) overproduction is held liable to be one of the key factors for the development of several diseases, including cancer. Tumor biology has revealed that most neoplasms have a much higher amount of reactive oxygen species than healthy ones, such as superoxide anion, $\mathrm{H}_{2} \mathrm{O}_{2}$, and hydroxyl radicals [37]. These reactive oxygen-containing chemicals react with nucleic acids, proteins, and lipids, contributing significantly to tumor cells proliferation, DNA alterations, apoptosis, metastasis, and angiogenesis [38-41].

As a consequence of the troubles produced by the existing chemotherapeutic agents, nowadays there is an increasing concern in the search for herbal formulation with cancer preventive effect. Indeed, studies are focusing particularly on fruits rich in polyphenols due to their anticancer potential [42].

In order to investigate the effectiveness of pomegranate and its derivatives as anti-proliferative, anti-invasive, and pro-apoptotic agents, several studies have been conducted on different cell lines, such as breast cancer lines (MCF-7 and MDA-MB-231), uterine cancer lines (HeLa and Ishikawa), colorectal adenocarcinoma lines (RKO), and animal models [43-45]. Some research groups have shown that the simultaneous use of skin, seed, and pomegranate juice extracts has a synergistic action in inhibiting cell proliferation in several in vitro models, such as: Human breast MCF-7, uterine HeLa, human prostate DU 145, and PC-3 cancer cells. [46,47]. This result has been confirmed by Hong et al. [48], who demonstrated that pomegranate extracts and juice components have a more potent action than the individual isolated polyphenols, suggesting that it is a synergistic and additive effect of many phytochemical compounds, among which proanthocyanidins, anthocyanins, flavonoids, and ellagitannins. The proanthocyanidins are strong antioxidant compounds that, after acid hydrolysis, can release catechins as (+)-(2R,3S)-catechin (1). They act synergistically with ascorbic acid, which gives therapeutic potential against neoplastic and cardiovascular diseases, since it is able to suppress the action of free radicals, as well as to protect the body from the development and metastasis of cancer (which in part depends on the damage caused to the DNA). The anthocyanins are derivatives of phenyl-4H-benzopyran-4-one and are present in the vacuoles of the epidermal cells of many plants [49]. These are characterized by a high chemical reactivity and very low toxicity. They have, in fact, an anti-free radical action and they modulate the arachidonic acid cascade by inhibiting cAMP-phosphodiesterase [49]. The main anthocyanins present in the pomegranate juice are: cyanidin (2), delphinidin (3), and pelargonidine-3-O-glucoside (4). It was shown that anthocyanins decrease the proliferation of colon cancer cells, HT-29, in a dose-dependent manner [5].

The flavonoids, present in the bark and skin responsible for the red color, have a very high antioxidant activity and are useful for blood circulation [50]. The main flavonoids are quercetin (5), which, in addition to an antioxidant action [51], also showed antiviral and cardioprotective effects [52,53], kaempferol (6), with anticancer properties, and the rutin (7), a molecule with antithrombotic properties [54]. Among the ellagitannins, ellagic acid (8), a highly thermostable molecule, can be extracted from pomegranate skin and possesses important biological activities including antitumor, antiviral, and antimicrobial [55]. In addition, it was shown that ellagic acid (8) induces cell lysis, apoptosis, and thus decreases cell viability due to DNA breakage and alterations in the cell cycle. Gonzalez-Sarrias et al. [56] have demonstrated that ellagic acid and its secondary products can contribute to the prevention of colon 
cancer by regulating the expression of multiple genes implicated in crucial processes linked to the development of cancer.

Another tannin, the punicalagin (9), is present almost exclusively in the skin. It has several pharmacological properties, among which are anti-inflammatory, anti-proliferative, pro-apoptotic, and anti-genotoxic [57]. It also induces apoptosis in colon cancer cells (cell lines: HT-29, HCT116) and prostate cancer cells at a concentration of $100 \mathrm{mg} / \mathrm{mL}$ [5]. A study with 46 patients with prostate cancer under experimentation showed, for 16 of them, a considerable decrease in PSA (prostate-specific antigen) during treatment with pomegranate juice [58].

Koyama et al. [59] report that treatment of LAPC4 prostate cancer cells with $10 \mu \mathrm{g} / \mathrm{mL}$ pomegranate extract, obtained from seedless arils and skin, and standardized to a $37 \%$ ellagitannin content in punicalagin, blocks cell proliferation and triggers apoptosis. Furthermore, pomegranate skin extract (PoPx) with a high concentration of ellagitannins provokes apoptosis in human breast cancer cells (MCF-7), estrogen receptor (ER)-positive (ER+).

In previous investigations, PoPx and genistein have shown significant inhibitory effects on the proliferation of breast cancer cells MCF-7. In addition, PoPx can impede cell proliferation and the expression of angiogenesis markers, phosphorylation of $\mathrm{p} 38$, and C-Jun protein kinases activated by mitogens, and the activation of pro-survival signaling pathways. PoPx inhibits the nuclear factor NF-kB gene expression, connected with proliferation, invasion, and motility in aggressive breast cancer phenotypes [60]. Aiyer et al. reported that treatment at a dose of $300 \mathrm{mg} / \mathrm{mL}$ of pomegranate fruit extract (PoMx) in combination with $1 \mu \mathrm{M}$ tamoxifen is able to reverse the resistance [61]. Moreover, recently Peng et al. identified PoMx as an interesting agent to cope up with oral cancer metastasis. Indeed, it was able to block wound healing migration, transwell migration, and matrix gel invasion. Analyzing the molecular mechanism, they also demonstrated that PoMx was able to downregulate matrix metalloproteinase MMP-2 and MMP-9 activities and expressions as well as epithelial-mesenchymal transition (EMT) signaling in HSC-3 cells [62].

PoPx prevent melanocyte proliferation and melanin synthesis by suppressing tyrosinase activity $\left(\mathrm{IC}_{50}=182.2 \mathrm{mg} / \mathrm{mL}\right)$. The amount of inhibition is comparable to arbutin, a glycoside with isoquinoline structure capable of being hydrolyzed in glucose and hydroquinone. An extensive amount of research has confirmed the ability of PoPx and ellagitannins to block the generation of free radicals in Ultraviolet (UV)A- and B-irradiated human skin, thus defending it from DNA fragmentation, from skin burns and depigmentation $[63,64]$.

In 2010, Dai et al. reported that pomegranate extract (PE) is able to inhibit in a time- and concentration-dependent manner (already at $10 \mu \mathrm{g} / \mathrm{mL}$ ) the viability and proliferation of a mouse mammary cancer cell line (WA-4, resulting from mouse MMTV-Wnt-1 mammary tumors) characterized by the presence of several cells possessing stem cells features. In particular, the arrest of cellular growth in the G0/G1 phase and an increased level of caspase 3 enzyme was observed, suggesting the mechanism of cell death by apoptosis.

Further investigations assessed the outcomes of individual phytochemicals derived from PE. Indeed, ellagic acid, ursolic acid (10), and luteolin (11) could contribute to the inhibitory potential of $\mathrm{PE}$, with an $\mathrm{IC}_{50}$ value of $10 \mu \mathrm{M}$. Instead, caffeic acid seemed to be inefficient [65].

Subsequently, in 2011, the same research group verified the arrest of cell growth due to PE but in the G2 phase by using as an in vitro model the human pancreatic cells PANC-1 and AsPC-1. The inhibition of cellular growth was already observed with an $\mathrm{IC}_{50}$ amounting to $50 \mu \mathrm{g} / \mathrm{mL}$ in both the lines, but individual phytochemicals were slightly responsible for it. However, data showed increased proportion levels of cells lacking of CD44 and CD24 (connected with high tumor-initiating ability), demonstrating that PE can modify cell phenotypes, reducing the tumorigenicity [66]. 
Motaal and Shaker assessed the antioxidant and anticancer properties of different PEs, highlighting that the peel extract possesses the best antioxidant activity with an $\mathrm{IC}_{50}$ value of $0.50 \pm 0.9 \mathrm{mg} / \mathrm{mL}$, and promising anticancer action toward MCF-7 breast cancer cells and HCT-116 colon cancer with $\mathrm{IC}_{50}$ values of $7.7 \pm 0.01$ and $9.3 \pm 0.06 \mu \mathrm{g} / \mathrm{mL}$, respectively [67].

In 2015, El-Awady and co-workers investigated the possible antitumor activity of two different extracts of Punica Granatum grown in Saudi Arabia. Their findings evidenced a good percentage of cellular growth inhibition at the maximum concentration tested $(100 \mu \mathrm{g} / \mathrm{mL})$ from both seeds and husks extracts, tested on hepatocellular carcinoma HepG2 (values amounting to 95.8 and 98.3\%, respectively) and colon cancer CACO cells (values amounting to 99 and $97 \%$, respectively). The whole cytotoxic profile exhibited a dose-dependent trend. The percentages of cellular growth inhibition permitted to determinate the corresponding $\mathrm{IC}_{50}$ values. They were 45 and $40 \mu \mathrm{g} / \mathrm{mL}$ on both HepG2 and CACO cells for pomegranate seeds and husks extracts, respectively [68].

Another study, performed by Modaeinama et al. in 2015, documented that the peel methanolic extract possesses a potent anti-proliferative action toward several tumor cell lines as: MCF-7 (breast adenocarcinoma), A549 (lung non-small cell cancer), SKOV3 (ovarian cancer), and PC-3 (prostate adenocarcinoma). The cytotoxicity has been investigated at different concentrations; the best antitumor effect was detected on MCF-7, with a percentage of survival inhibition amounting to $83.7 \%$ at doses of $5 \mu \mathrm{g} / \mathrm{mL}$. Instead, for the other cell lines, this percentage was 77.87, 76.54, and 63.41\% for PC3, A549, and SKOV3, respectively, at the same dosage used for MCF-7 [69].

Research based on the possible effect of a PE on chronic myeloid leukemia surveys that it is able to suppress cell growth by activating apoptosis and inducing cell cycle arrest. The findings of the research group led by Asmaa, outlined that the peel extract of pomegranate could inhibit K562 cell growth in a dose-dependent manner, with total cell death at the maximum concentration tested and an $\mathrm{IC}_{50}$ value of $100 \pm 0.05 \mu \mathrm{g} / \mathrm{mL}$. Further investigations have assessed the ability of the extract to induce the cell cycle arrest in the G2/M phase and apoptosis. Indeed, an upregulation of proapoptotic proteins caspases $9,7,3$, and cytochrome $\mathrm{c}$, and a downregulation of antiapoptotic protein Bcl-2 were detected [70].

In depth studies of genetics appraised the possible influence of PE on immunoregulatory-related miRNAs level of adipose-derived MSCs (Ad-MSCs) obtained from adipose tissue. Data suggested that the principal mechanism of action could be due to the capability to decrease the expression of $\mathrm{PI} 3 \mathrm{~K} \backslash \mathrm{AKT} 1 \backslash \mathrm{NF}-\mathrm{kB}$ genes involved in inflammatory pathways via miRNAs expression. It plays a role in the immune modulation in Ad-MSCs. In other words, PE could possess a key role in regulating the immunomodulatory function of stem cells [71].

A new approach in the use of phytochemicals for the cancer fighting lies in the knowledge of preparing metal-based nanoparticles from the extract of different plant parts, using green synthesis procedures. Indeed, silver nanoparticles possess the capability to up- and downregulate several cellular mechanisms, and this has propelled to the forefront in investigations to use them as a possible delivery system for other chemicals or as real control systems for the cellular growth [72-74].

In 2018, Sarkar and Kotteeswaran carried out the green synthesis of silver nanoparticles from the aqueous leaf extract of pomegranate, in order to test their capability as anticancerous toward human cervical cancer cells (HeLa). Their findings have proven that this kind of delivery system is able to inhibit cell growth in a dose-dependent manner with an $\mathrm{IC}_{50}$ value of $100 \mu \mathrm{g} / \mathrm{mL}$. Moreover, they assessed the ability of these pomegranate nanoparticles to induce necrosis and apoptosis by detecting increased levels of lactate dehydrogenase and DNA fragmentation [75].

Recently, Yusefi et al. employed four different weight \% of Punica granatum fruit peel extract as green stabilizers to produce iron oxide nanoparticles (IONPs) and investigated their potentiality as anticancer agents. Among all the cell lines tested, IONPs have been shown to have a powerful inhibitory effect against nasopharyngeal carcinoma (NPC) cell line, HONE1. In particular, the most active IONPs, containing 2 and $4 \mathrm{wt} \%$ of peel extract, exhibited $\mathrm{IC}_{50}$ values amounting to 197.46 and $85.06 \mathrm{mg} / \mathrm{mL}$ respectively [76]. 
All the data reported contribute to a vision of the state of the art in this field, remarking the potential antiproliferative effect of different parts of this fruit on a large panel of tumoral cells. However, in vivo studies, nowadays lacking, could be important to upgrade the researches.

\subsection{Anti-Inflammatory Properties}

Inflammation represents the first physiological response against injuries caused by physical agents, poisons, and others. [5,77-79]. The defense system, the so-called primary inflammation, neutralizes infectious microorganisms, removes irritation, and maintains ordinary physiological functions [80]. The phlogosis is triggered by various chemical and biological agents, including pro-inflammatory enzymes and cytokines, such as eicosanoids or degradation products of inflamed tissue.

According to recent reports, pomegranate exhibited potential as an anti-inflammatory medicine in both in vitro and in vivo studies. Some extracts of pomegranate, especially the cold-pressed seed extract, decrease the action of cyclooxygenase and lipoxygenase enzymes in vitro. Cyclooxygenases are useful enzymes for the degradation of arachidonic acid into prostaglandins, key mediators of inflammation. Lipoxygenase, on the other hand, mediates the transformation of arachidonic acid into leukotrienes and it is reduced by extracts of pomegranate seeds [81,82].

Bousetta et al. [83] report that punicic acid (12), a fatty acid contained in pomegranate seed oil, has an anti-inflammatory activity due to the inhibition of neutrophil activation, and therefore limits lipid peroxidation.

Lee et al. [80] analyzed some hydrolyzable tannins, including punicalagin (9) and punicalin (13), isolated from pomegranate by fractionation. Following in vitro studies, each of these compounds exerted a dose-dependent inhibitory effect on nitric oxide synthesis with an important anti-inflammatory effect [84].

De Nigris et al. [85] have shown that the dietary inclusion of pomegranate fruit extract caused an important reduction in expression of the markers of vascular inflammation, thrombospondin, and cytokine transforming growth factor (TGF- $\beta 1$ ) in obese Zucker rats, a model of metabolic syndrome.

Larossa et al. [86] indicated that pomegranate composition could prevent colon inflammation before and during the disease process. They assessed the consequences of pomegranate intake and its main microbiota-derived metabolite urolithin-A (UROA) on colon inflammation. Results suggested that URO-A could represent the most powerful anti-inflammatory compound derived from pomegranate ingestion in healthy subjects, whereas in colon inflammation, the effects could be caused by the nonmetabolized ellagitannin-related fraction. Additionally, pomegranate extract supplementation has been shown to lead to decreased levels of prostaglandin E2 in the colon mucosa due to reduced cyclooxygenase-2 (COX-2) overexpression and diminished levels of prostaglandin synthetase E (PTGES) due to high ellagic acid (8) content [87].

Park et al. analyzed the effects of pomegranate peel extract (PPE) on THP-1 monocytic cells exposed to PM10, air-borne particulate matter with a diameter of $<10 \mu \mathrm{M}$ (PM10) that are known to induce cytotoxicity and ROS production and also to increase the expression and secretion of inflammatory cytokines, such as TNF- $\alpha, \mathrm{IL}-1 \beta$. This study demonstrated that PPE at $10-100 \mu \mathrm{gmL}^{-1}$ is able to lower the production of ROS and the expression of TNF- $\alpha$, IL-1 $\beta$, MCP- 1 , and ICAM- 1 thus preventing inflammatory events due to particulate matter [88].

A recent study by $\mathrm{Xu}$ et al. explore the inflammation effects of pomegranate flower (PFE) ethanol extract in lipopolysaccharide (LPS) -induced RAW264.7 cells. LPS is a component of the Gram-negative bacteria cell wall that has been often used in inflammatory response because it can activate macrophages. Their findings suggest that PFE is able to suppress the production of NO, PGE-2, and pro-inflammatory cytokines (TNF- $\alpha$, IL-6, IL-1 $\beta$ ), as well as the protein expression of iNOS and COX-2 in LPS-stimulated RAW264.7 macrophages. Furthermore, PFE treatment markedly inhibited LPS-induced NF-kB activation through blocking nuclear translocation of NF-kB and IkB $\alpha$ degradation and PFE treatment also inhibited the phosphorylation of mitogen-activated protein kinases (MAPKs) [89]. 
Kim et al. demonstrated the advantageous protective outcomes of pomegranate beverages, in comparison with those of mango in a preclinical model of colitis. The results obtained suggested that extracts rich in gallo- and ellagitannins work on several molecular targets in the protection against ulcerative colitis. Mango polyphenols inhibited the IGF-1R- AKT/mTOR via, and pomegranate polyphenols downregulated the mTOR downstream pathway, decreasing the ERK1/2 expression [90].

The systemic effects of PE on the formalin-induced nociceptive behavior and against gastric injury generated by non-steroidal anti-inflammatory drugs and ethanol in mice have been investigated. PE provide antinociceptive and anti-inflammatory activities without damaging the stomach and even displaying gastroprotection, possibly by modulation at central and peripheral levels [91].

The topical anti-inflammatory effect of a standardized pomegranate rind extract (SPRE), toward a mouse model of contact dermatitis has been evaluated, in relation to its marker compound ellagic acid, by Mo et al. The results highlighted the powerful anti-inflammatory activity of topical application of SPRE, ellagic acid being responsible for the extract activity as its major antioxidant constituent. The study suggests the topical formulation of SPRE as a promising therapy for contact dermatitis and as an alternative therapy for cutaneous disorders [92].

All these researches highlight the ability of the different components present throughout the pomegranate fruit to act as anti-inflammatory agent. However, further studies are required to completely exploit pomegranate's preventive and therapeutic potential in vivo.

\subsection{Antidiabetic Activity}

Diabetes is the principal widespread metabolic disease in the world and its occurrence has a rising trend. According to the World Health Organization, it is the third most common disorder after cardiovascular and oncological diseases [93].

Diet allows for the control of diabetes mellitus, and pomegranate fruit and its derivatives are part of it [56].

Among antidiabetic molecules, polyphenols, contained in pomegranate, are able to lower glycemic values, including via the reduction of glucose absorption through the intestine or peripheral tissues, although the most likely mechanism is the decrease of the enzyme glucosidase [94].

$\mathrm{Li}$ et al. [95] have hypothesized that pomegranate flower extract improves post-prandial hyperglycemia in type 2 diabetes and obesity, at least partially, as a result of the suppression of intestinal $\alpha$-glucosidase activity.

Huang et al. [96] instead reported a plausible mechanism of the antidiabetic activity of the PFE involving the activation of PPAR- $\gamma$. In addition, caffeic acid (17) or 3,4-dihydroxycinnamic acid another component of PE, increases the uptake of glucose by adipocytes in rats and myoblasts in mice [5].

Finally, McFarlin et al. [97] explored the impact of pomegranate seed oil on fat storage in mice noticing an enhancement of insulin sensitivity.

Parmar and Kar went into the potential effect of pomegranate peel extract on tissue lipid peroxidation (LPO), the concentration of thyroid hormones, insulin, and glucose in male rats starting from in vitro evaluations, which proved an inhibition of $\mathrm{H}_{2} \mathrm{O}_{2}$-induced LPO in red blood cells of rats by $0.25,0.50,1.0$, and $2.0 \mu \mathrm{g} / \mathrm{mL}$ in a concentration-dependent manner. The maximum was achieved at $2.0 \mu \mathrm{g} / \mathrm{mL}$. In vivo, P. granatum reduced LPO in hepatic, cardiac, and renal tissues and serum glucose concentration. These data suggested a potential regulatory role of this peel extract on thyroid function and glucose metabolism [98].

Another study assessed the ability of pomegranate fruit extract to decrease the serum resistin levels (adipocytokine, seen as a possible connection between obesity and type 2 diabetes) in ovariectomized mice, an animal pattern presenting exalted resistin levels in serum and upregulated resistin mRNA expression in white adipose tissue. Furthermore, PoMx was able to reduce the secretion and intracellular levels of resistin in differentiated murine 3T3-L1 adipocytes, without modifying resistin mRNA expression. Other findings suggested that PFE stimulated the degradation of resistin. All these activities could be mainly attributed to ellagic acid [99]. 
Several studies agree that oxidative stress triggered by diabetes mellitus gives rise to brain damage. Indeed, Cambay et al. indicated that the co-administration of pomegranate flower extract and antidiabetics resulted into improvements in learning and memory performances of diabetic rats. Moreover, in test subjects in which LPO was increased and glutathione (GSH) content was diminished in hippocampal tissue, the supplementation of pomegranate flower extract PGF was able to restore these levels. Besides, daily PGF intake decreased glial-fibrillar acidic protein contents induced by diabetes in the hippocampus [100].

On the contrary, in 2016, a research team questioned these findings, corroborating that daily consumption of pomegranate seed oil in patients suffering from diabetes mellitus 2 did not substantially impact the levels of parameters such as fasting blood sugar (FBS), insulin, HbA1c, alanine transferase, and homeostasis model assessment-insulin resistance [101].

PFE has been, over the years, part of the Chinese diet as an ally against type 2 diabetes mellitus (T2DM). For this reason, Tang et al. tried to analyze the kind of activity implied in the antidiabetic effect. The rat model (male Sprague-Dawley (SD) rats) diet was implemented with PFE polyphenols extract at doses of 50 and $100 \mathrm{mg} / \mathrm{kg}$ for a period of 4 weeks. Several assays as oral glucose tolerance test (OGTT), insulin tolerance test (ITT) and homeostasis model assessment of insulin resistance (HOMA-IR) were performed, revealing an improvement of insulin sensitivity. Deeper molecular investigations established that insulin-signaling activity was enhanced with an elevation in insulin-stimulated phosphorylation of insulin receptor substrate (IRS-1), Akt, and GSK-3b. Additionally, they assessed a decrease, after the treatment, of endoplasmic reticulum (ER) stress signals including phosphorylation of inositol-requiring kinase1 (IRE1) and activation of X box-binding protein (XBP-1) splicing. In addition, regarding the blood lipid profile, liver glycogen content and antioxidant status were improved by PFE in the rats [102].

Similar results were found for pomegranate fruits aqueous extract as a conspicuous decrease in fasting blood glucose (FBG) by 28.1 and $67.9 \%$ in short-term and long-term treatment models (alloxan-diabetic male Wistar rats) and a raise in the mRNAs expression levels of IRS-1, Akt, Glut-2, and Glut-4, suggesting an improvement of glucose uptake and storage [103].

Recently, the potential combination of pomegranate juice and Lactobacillus casei NRRL-B-1922 (used as fermenting agent) to create a functional juice able to combat T2DM has been documented. The results highlighted that pomegranate could support the growth of L. casei even without nutrient supplementation. Further analysis demonstrated that the glucose and fructose contents were gradually lowered with consumption rates of 0.51 and $0.37 \mathrm{~g} / \mathrm{L} / \mathrm{h}$, respectively, in the bioreactor. Moreover, the possible antidiabetic mechanism of action could be attributable to the dipeptidyl peptidase-4 (DPP-4) inhibition (with a rate of 80\%). Indeed, DPP4 is a well-known target of many antidiabetic agents [104].

A recent clinical trial demonstrated that the assumption of pomegranate juice in patients with T2D can change and lower erythropoietin levels just after $3 \mathrm{~h}$ of ingestion whereas no modifications were observed in healthy patients [105]. However, further studies to assess the long-term antidiabetic effects of the pomegranate consumption are in progress.

\subsection{Antimicrobial Activities}

Antimicrobial agents are mainly applied on microorganisms that cause food poisoning (infected or toxin-producing agents) and on microorganisms that alter food by producing final metabolic products (catabolites) or enzymes with bad odor, unpleasant taste, problems of persistence, different coloring, and/or health risk [106].

The antimicrobial effect of pomegranate and its products has been demonstrated in a large amount of research [107], in particular, polyphenols, flavonoids, and condensed and hydrolysable tannins derived from the fruit have been studied as promising agents to treat or prevent a broad range of infections [108]. 
The antimicrobial mechanisms of phenolic compounds engage the reaction of phenols with sulfhydryl groups of membrane proteins of the microbial cell, inducing a bactericidal effect due to membrane protein precipitation and inhibition of enzymes such as glycosyltransferase [109].

Food-borne disorders and urinary tract infections are treated typical in the Indian subcontinent through PoPx, while ellagitannins, punicalagin (9), ellagic acid (8), and gallic acid (18) in the pomegranate skin, as natural antimicrobial agents, have been extensively used against Staphylococcus aureus and Escherichia coli hemorrhages for their capability to precipitate membrane proteins and block enzymes such as glycosyltransferase, causing lysis. In vivo and in situ application of an $80 \%$ pomegranate skin (PoPx) methanol extract showed a growth reduction against Listeria monocytogenes, Staphylococcus aureus, Escherichia coli, and Yersinia enterocolitica. However, it has been reported that higher doses of PoPx $(24.7 \mathrm{mg} / \mathrm{mL})$ represent the lowest bactericidal concentration of Listeria monocytogenes [110].

Another study evidenced the powerful effect of Punica granatum L. peels' ethanolic extract (Tunisian Nana variety) against two Salmonella strains, Salmonella Enteritidis and Salmonella Kentucky, microorganisms resistant to the majority of antibiotics. Minimal inhibitory concentration (MIC) values ranged from 10.75 to $12.5 \mathrm{mg} / \mathrm{mL}$ regarding both strains. In particular, the inhibitory effect achieved by peel extract (using hydroethanolic and hydromethanethanolic mixtures) on Salmonella Kentucky achieved inhibition diameters of 22.2 and $22 \mathrm{~mm}$, respectively [111].

Višnjevec et al. explored and evaluated the antimicrobial properties of ethanol and water extracts of pomegranate exocarp and mesocarp from Istria. The best antibacterial activity was recorded, here too, for ethanolic extract. Indeed, the microorganisms more susceptible to this extract were C. albicans, C. parapsilosis, R. mucilaginosa, E. dermatitidis, and S. aureus, with MIC ranging from 0.156 to $1.25 \mathrm{mg} / \mathrm{mL}$. Instead, the best antimicrobial activities of the exocarp and mesocarp water extracts were found toward S. aureus, followed by E. coli without any antifungal activity [112].

Another use of pomegranate peel extract as antimicrobial agent involved its participation in the synthesis of silver nanoparticles. The latter, due to the use of transmission electron microscopy (TEM) and scanning electron microscopy (SEM), demonstrated to be evenly distributed in the solution, with a spherical shape and size ranging from 20 to $40 \mathrm{~nm}$ and with an average particle size of $26.95 \mathrm{~nm}$. Subsequently, tests evidenced the capability of nanoparticles to substantially inhibit Gram-negative and Gram-positive bacteria as E. coli, P. aeruginosa, P. vulgaris, S. typhi, S. aureus, S. epidermidis, and K. pneumonia already at 25 and $50 \mu \mathrm{g} / \mathrm{mL}$ [113].

As can be evinced from this section, pomegranate and, in particular, the peel extract, exhibited antimicrobial effects against a wide spectrum of bacteria. Unfortunately, in order to become effectively beneficial for the pharmaceutical field, much more has to be done regarding the deepening of the mechanism of action.

\subsection{Prevention of Cardiovascular Diseases}

The main risk factors for the occurrence of coronary diseases is dyslipidemia, characterized by an excessive increase in low-density lipoproteins (LDL) and/or low levels of high-density lipoproteins (HDL) $[114,115]$.

It is known that LDL oxidation contributes to atherosclerosis and the development of cardiovascular diseases $[53,116]$.

Inhibition of LDL oxidation is considered a promising way to avoid the storage of foaming cells and, ultimately, cholesterol deposits in the arteries.

Due to its formidable antioxidant capacity, the extract obtained from the pomegranate skin has the power to suppress LDL oxidation and thus delay the advancement of atherosclerosis with an important decrease in foaming cell levels at the artery level. 
The polyphenols present in pomegranate, punicalagin (9), gallic acid (18) and, to a lesser extent, ellagic acid (8), increase the expression and secretion of the liver enzyme paraoxonase 1 in a dose-dependent manner, thus reducing the risk of developing atherosclerosis [117].

Riaz and Khan in 2016 gave an insight into the anticoagulant, antiplatelet, and antianemic effects of Punica granatum juice by studying the hematological profile of the rabbits used as an in vivo model. Their findings evidenced a substantial increase in erythrocyte count, mean corpuscular hemoglobin concentration after 30 days of treatment, whereas red cell distribution width was significantly reduced. Instead, leucocyte count, hematocrit (Hct), mean corpuscular volume (MCV), mean corpuscular hemoglobin (MCH), and platelet count (PLT) were not modified at any dose. Furthermore, there was an important increase in bleeding time both after 30 and 60 days, and a significant rise in thrombin time (TT) and activated partial thromboplastin time $(\alpha \mathrm{PTT})$ after 60 days, whereas prothrombin time did not change. Comparing the pomegranate ability in lowering cholesterol and the prolonged $\alpha$ PTT time, they speculated that the cholesterol reduction induced by P. granatum may lead to a decrease in the concentration of coagulation factors, influencing, in this way, $\alpha$ PTT. In conclusion, data illustrated that P. granatum significantly inhibited aggregation of platelets induced by adenosine diphosphate ADP and epinephrine (Epi) in the blood samples of animals treated already at $2 \mathrm{~mL} / \mathrm{kg}$ for 30 and 60 days [118].

The hypothesis that pomegranate ameliorates the cardiac function has been also supported by Razani et al. Indeed, they administered $220 \mathrm{~mL}$ of pomegranate juice to one hundred hospitalized patients suffering from unstable angina or myocardial infarction for 5 days in order, a the end, to evaluate cardiac markers and parameters. The results indicated a significant reduction in the intensity, occurrence, and duration of angina pectoris in patients with unstable angina. Moreover, the measurement of serum levels of troponin and malondialdehyde revealed a decrease of these factors. Nevertheless, other parameters like interleukin-6,tumor necrosis factor alpha, blood pressure, and heart rate were not affected [119].

More recently, the possible interaction between ethanolic peel extract of Punica granatum and doxorubicin (well known for its cardiotoxicity) was evaluated. The assessment was performed by measuring heart weight/body weight ratio, biochemical parameters, and histopathological changes. After the treatment with $100 \mathrm{mg} / \mathrm{kg}$ body weight, an increased heart weight/body weight ratio, in comparison with the doxorubicin-treated group, was observed as well as blood and tissue glutathione, superoxide dismutase, and catalase levels. On the contrary, creatine kinase, lactate dehydrogenase enzyme, and malondialdehyde levels appeared significantly reduced. Concerning the histopathological morphology, the only assumption was that doxorubicin modified myocardium through vacuolar alterations in the heart muscle and necrosis of heart muscle with remote cells increasing in the size in between the necrotic and fragmented muscle fibers. Instead, treatment with P. granatum peel extract displayed a protective effect with less histological changes such as irregular and spread vacuolation limited to subendocardial layers [120].

A recent clinical trial evidenced that the consumption of pomegranate juice improves the lipid profile and oxidative and inflammatory biomarkers of hemodialysis patients. The results outlined that triglycerides were decreased in the pomegranate juice condition and augmented in the control groups. On the other hand, high-density lipoprotein cholesterol was increased after PJ assumption, whereas total and low-density lipoprotein cholesterol were not affected. Systolic and diastolic blood pressure dramatically fell in the PJ condition, while total antioxidant capacity increased [121].

These data were also supported by Sohrab et al., who found in their study a decrement of systolic blood pressure and diastolic blood pressure; whereas, total cholesterol, low-density lipoprotein cholesterol decreased significantly compared to pre-trial values within the intervention group [122].

All these findings demonstrate the importance of pomegranate juice dietary supplementation in modulating cholesterol levels and preventing cardiovascular diseases. 


\subsection{Antiviral Activities}

The hydrolysable tannins of pomegranate, including punicalin (13), punicalagin (9), gallic acid (18), and ellagic acid (8), have antiviral properties capable of modulating respiratory infections and influenza.

The antiviral properties of the polyphenolic extract of pomegranate are due to the inhibition of influenza virus RNA replication [117,123].

Similarly, phenols in the skin inactivate viruses through direct structural damage and indirect intercellular inhibition of viral replication. The virucidal effects of pomegranate phenolic compounds imply their interaction with the antigenic glycoprotein, hemagglutinin, present on the surface of some viruses (es. influenza viruses), which produce a loss of red blood cell agglutination [124].

In particular, Haidari et al. argued that punicalagin (9) is the effective component of pomegranate polyphenol extract able to block replication of the virus RNA, inhibit agglutination of chicken red blood cells (RBCs) by the virus of influenza H3N2, and have viricidal activity. They also investigated the potential synergistic effect of pomegranate polyphenol extract and oseltamivir (a well-known antiviral agent), outlining that oseltamivir in association with pomegranate polyphenol extract amplificated its anti-influenza power [125].

Sundararajan et al. in 2010 confirmed and implemented these data, strengthening that the direct anti-influenza activity of pomegranate polyphenols (PPs) is principally an outcome of PP-induced virion structural damage. Indeed, these components of pomegranates quickly block the influenza virus through a direct effect on the viral particle. They also suggested that this action might be separate from effects on hemagglutinin (HA) function. Moreover, they demonstrated the efficacy of pomegranate PPs against H1N1 and H3N2 influenza viruses and against the reassortant H5N1 virus rg-VN/04 [126].

Furthermore, another study attributed to punicalagin the power to reduce the viral cytopathic effect on rhabdomyosarcoma cells, calculating an $\mathrm{IC}_{50}$ value of $15 \mu \mathrm{g} / \mathrm{mL}$. This effect was also assessed in vivo, noticing a decrease of mortality in mice treated with a lethal dose of enterovirus 71 [126].

Reddy et al. focused on the potential effect against hepatitis $\mathrm{C}$ virus (HCV) of the ellagitannins extracted from pomegranate (Punica granatum) fruit peel. In particular, pure compounds punicalagin, punicalin, and ellagic acid exhibited in vitro the capability of blocking the HCV NS3/4A protease activity in a concentration-dependent manner with $\mathrm{IC}_{50}$ values of less than $0.1 \mathrm{mM}$ (for punicalagin and punicalin), whereas $\mathrm{IC}_{50}$ for ellagic acid was achieved at $1.0 \mathrm{mM}$. These data were confirmed through in silico studies and observing a consistent reduction of HCV replication in cell culture systems. Data ex vivo pointed out the optimal bioavailability and the toxicity absence of these compounds [127].

In addition, a good activity of pomegranate extract toward adenovirus has been found. The $\mathrm{IC}_{50}$ and $\mathrm{CC}_{50}$ (50\% cytotoxicity concentration) were estimated on HeLa cells with values of $165 \pm 10.1$ and $18.6 \pm 6.7 \mu \mathrm{g} / \mathrm{mL}$, respectively, whereas the selectivity index (SI, calculated as the ratio of $\mathrm{CC}_{50}$ and $\mathrm{IC}_{50}$ ) on adenovirus amounted to 8.9 [128].

In their analysis, Houston et al. investigated the co-administration effects of pomegranate rind extract in conjunction with zinc (II) salts in order to challenge herpes simplex virus HSV-1 and its aciclovir-resistant. Data showed a potentiation factor by up to 5.5 -fold. Regarding aciclovir-resistance, pomegranate rind extract exhibited an $\mathrm{EC}_{50}$ value amounting to $0.02 \mu \mathrm{g} \mathrm{mL} \mathrm{L}^{-1}$, whereas acyclovir displayed no activity [129].

Given the several reported studies that have proven the antiviral effects of pomegranate, Arunkumara and Rajarajanb surmised the possible inhibitory effect of Punica granatum against Herpes simplex virus-2 (HSV-2). In effect, their findings assessed that ethanolic peel extract suppresses HSV-2 at a concentration of $62.5 \mu \mathrm{g} / \mathrm{mL}$. In order to understand the real responsibility of this action, the extract was subjected to bioactive compounds separation by bioassay-guided fractionation. Then, the single components were tested as antivirals. The key component for the activity seemed to be punicalagin, showing a total inhibition rate at $31.25 \mu \mathrm{g} / \mathrm{mL}$. Moreover, bioactive compound analysis using the ADMET tool, established that human intestinal absorption (HIA) properties of acyclovir (ACY), gallic acid (GA), and ellagic acid (EA) had moderate adsorption values of 63.77, 53.69, and 61.39\%, respectively, and punicalagin presented very strong plasma protein binding. In addition, docking 
studies highlighted that the most active component could interact with HSV-2 amino acids through several hydrogen bonds [130].

The global pandemic due to the spread of the severe acute respiratory syndrome coronavirus 2 (SARS-CoV-2) has dramatically shaped queries on the necessity to find as soon as possible a cure for this disease. With this in mind, many efforts, also with the aid of artificial intelligence, have been made to discover molecules able to interact with the viral proteins and cause the Sars-CoV-2 inhibition. Several compounds of natural origin were found to be able to do this. Among them, docking studies revealed that the ellagic acid, one of the already mentioned main components of pomegranate, has the potentiality to interact with important proteins involved in Sars-CoV-2 as RNA-dependent RNA polymerase (RdRp), angiotensin-converting enzyme 2 (ACE2), spike glycoprotein (SGp), and main protease (3CLpro) [131,132].

Furthermore, another study conducted on the viral main protease (3-chymotrypsin-like cysteine enzyme), held responsible for the COVID-19 control of duplication and life cycle management, assessed the potential of hydrolysable tannins (present also in pomegranate) as its natural inhibitors. Indeed, punicalin seems to establish H-bonds with the crucial catalytic residues of pocket spatial position [133].

From this research, it is deduced that pomegranate (especially peel extract) possess a prophylactic potential against viral epidemics and pandemics, specifically influenza. This may open up new avenues for research in the nutritional and medical science fields if the studies are made complete with in vivo experiments.

\subsection{Other Properties}

\subsubsection{Obesity}

Obesity is a chronic disorder of multiple factors characterized by an extensive accumulation of fat or general hypertrophy of adipose tissue in the body [134]. Hence, obesity can be so described when the natural energy reserve of humans or other mammals stored in the form of body fat increases to such an extent that it is associated with a series of complications, health problems, diseases, and even an increase in the mortality rate [135].

Studies have been carried out showing that the consumption of pomegranate leaf extracts, in particular punicalagin (9), diminishes the sense of hunger and body weight [136], and that the extract inhibits the incidence of obesity and hyperlipidemia. These activities seem to be due partially to inhibition of pancreatic lipase and partly to a decreased calorie intake [137].

Khabeer et al. went through the anti-obesity potential of SHAMstat3pg, a fatty acid composite extracted from pomegranate seed oil, made up of punicic acid, oleic acid, and linoleic acid. Their findings established that the treatment of $10 \mu \mathrm{g} / \mathrm{mL}$ of SHAMstat3pg $(24 \mathrm{~h})$ inhibited in a dose-dependent manner adipogenesis of human adipose derived mesenchymal stem cells (HADMSC), improved inflammation, attenuated ATP production, and glucose uptake. In addition, the extract favorably modulated the mRNA expression of the studied obesity-associated gene transcripts [138].

Several positive effects on fat reduction have been underlined, maybe for the presence of anthocyanins, tannins, and numerous antioxidant compounds. However, given that obesity is classified as one of the main risk factors for the development many disorders (metabolic and not), human studies in this field are still limited and need more attention to understand the preventive role of pomegranate in order to make it a potent nutraceutical ally.

\subsubsection{Intestinal Regulation}

Pomegranate derivative intake leads to a considerable accumulation of ellagitannins in the large intestine, where they react with the intestinal microflora [139]. Bialonska et al. [140] reported that the beneficial effects on microflora are mainly due to PoPx. A well-known cause of intestinal damage is represented by high-intensity exercise. In order to overcome this risk, Chaves et al. studied the consequences of the assumption of fermented milk supplemented with whey protein 
(approximately $80 \%$ protein), probiotic (Bifidobacterium animalis subsp. lactis BB12), and pomegranate juice (Punica granatum L.) on the physical performance, intestinal motility and villi structure, inflammatory markers, and intestinal microbiota of in vivo model Wistar rats under high-intensity acute exercise. The group only subjected to exercise went through changes in the intestinal villi interspace, in the proportion of Lactobacillus species and an increase in Clostridium species, as well as a decrease in intestinal motility. The treated group, instead, ameliorated intestinal motility and preserved the intestinal villi interspace and the natural microbiota proportions, but the physical performance was not enhanced [141].

In 2019, George et al. demonstrated the capability of pomegranate peel extract to constrain the pathogenicity of Citrobacter rodentium $(\mathrm{Cr}$ ) infections. The results obtained underlined a discrepancy between mice treated with pomegranate peel extract and the control group regarding the composition of the microbiome. Indeed, in treated animals, a reduced proportion of Firmicutes/Bacteroidetes was found by increasing Bacteroidetes and decreasing Firmicutes amounts, which led to a large reduction in Lactobacillus. These alterations have led to the belief that the intake of pomegranate could play a protective function against various intestinal infections [142].

Similar findings have been evidenced by Smith et al. which assessed that the treatment pomegranate peel extract was able to reduce Cr infections, weight loss, and mortality with respect to whom assumed just water as control groups. Instead, the treatment did not alter Cr colonization of the colon, whereas it reduced the colonization of the spleen. Moreover, it lowered the degree of Cr-induced colon damage, associated with mortality [143].

Nevertheless, the advances made to understand the capability of pomegranate to influence the microbiota remain limited still and need to be deepened in vivo.

\subsubsection{Effects on the Male Reproductive System}

According to Türk et al. [144], the consumption of pomegranate juice produces an increase in the concentration of sperm in the epididymis, higher sperm mobility and density, and a reduction of poor quality sperm compared to the reference or control group. In a more recent study, this same group of researchers suggested that ellagic acid (8) has a protective effect on both testicles and sperm. This effect may be connected to the powerful action of ellagic acid against oxidative stress [145]. Concerning erectile dysfunction or impotence, the continued inability to achieve or maintain an erection sufficient to maintain satisfactory sexual intercourse, Forest et al. [146] stated that after four weeks of treatment with pomegranate juice, patients showed better erectile activity than others who had received a product with a placebo effect.

However, this field the knowledge is still limited, and other studies are necessary to assess the veracity of this hypothesis.

\subsubsection{Antidiarrheal Effects}

Qnais et al. [147] assessed the antidiarrheal effects of the water extract of pomegranate fruit skin on rats. The outcomes demonstrated that the extract dose-dependently inhibits spontaneous ileum movements and attenuates acetylcholine-induced contractions.

In other studies, the antidiarrheal effects of fruit skin on rats were evaluated by administering an oral dose of $400 \mathrm{mg} / \mathrm{kg}$. The findings showed that pomegranate extract decreases the number of defecations and stool weight [148].

These previous findings were also supported by Zhao et al. in 2018 by studying the aqueous extract of pomegranate peels and, in particular, its bioactivity-guided fractions and bioactive components. The fraction considered responsible of the antidiarrheal activity was the ethyl acetate one, mainly composed by punicalagin, corilagin, and ellagic acid. Data also revealed that the administration of the ethyl acetate fraction at 100, 200, and $400 \mathrm{mg} / \mathrm{kg}$ was able to decrease gastrointestinal transit in charcoal meal tests in mice as well as inhibit castor oil-induced enteropooling compared to control 
animals. From histopathological evaluations, it emerged that small intestine lesions of mice treated with the ethyl acetate fraction were relieved in comparison to those in mice treated with castor oil [149].

Although the studies in this sector are insufficient, they suggest the potentiality of pomegranate in regulating intestinal motility.

\subsubsection{Effects on Oral Health}

Currently, science recognizes that chronic periodontal inflammatory disorder is strictly linked to the worsening of cardiovascular disease [150].

DiSilvestro et al. [151] have demonstrated that an oral rinse based on extracts of pomegranate would significantly reduce (about $84 \%$ ) the number of microorganisms from the dental plaque.

Sastravaha et al. [152] have highlighted the efficacy of a toothpaste containing pomegranate extracts as an additional treatment to complement routine periodontal therapies and have demonstrated that pomegranate flavonoids have an in vitro antibacterial property against the microorganisms responsible for gingivitis.

Nonetheless, there is still ample scope for research in this field.

\subsubsection{Effects on Pregnant and Breast-Feeding Women}

Recent studies demonstrated the importance of a nutritional supplementation with pomegranate.

In particular, Al-Wazni et al. assessed the potential beneficial effects of three types of pomegranate extracts to fight urinary tract infections. Indeed, their findings demonstrated that the pomegranate peel extracts were able to inhibit S. aureus and E. coli bacteria, pathogens common to the urinary tract, in comparison to ciprofloxacin, used as reference molecule, and the negative control was represented by distilled water [153].

In 2017, Manouchehrian et al., through a clinical trial conducted on 80 healthy pregnant women, demonstrated the potential effect of adding pomegranate paste to pregnant women's diets on the incidence of neonatal jaundice. Indeed, the results revealed decreased values of bilirubin in the group fed with pomegranate paste with respect to control group [154].

A study carried out on pomegranate juice maternal supplementation, famous to be enriched with antioxidants and bioactive polyphenols, hypothesized the potential improvement of uterine and umbilical artery function with the consequent enhancement of fetal growth in the $\mathrm{eNOS}^{-/-}$mouse model of fetal growth restriction (FGR) without increasing fetal weight [155].

Similarly, Henning et al. envisaged the presence of one of the main pomegranate constituents, ellagic acid and its metabolites, in breast milk after the consumption of 8 ounces per day of pomegranate juice. As expected, they found detectable levels of ellagic acid and metabolites in breast milk after 14 days of nutritional supplementation. This could mean that the phenolic compounds delivering through breast milk could enhance infant health and development [156].

Needless to say, pomegranate represents an inexhaustible source of benefits, but for a safe use as therapeutic agent on pregnant and breast-feeding women other studies must be carried out.

\subsubsection{Effects on Nervous System}

Prior research considered neuroinflammation as the principal factor responsible for neurodegenerative diseases, including Alzheimer's and Parkinson diseases, as a consequence of neuronal degeneration after over-activating microglia in the brain [157].

Recent studies have promoted the neuroprotective activity of pomegranate due to the presence of several well-known anti-inflammatory components previously mentioned in the text (see Section 2.2). 
In this context are well inserted the investigations carried out by DaSilva et al. in 2017. Their findings substantiated that urolithins, ellagitannin-gut microbial-derived metabolites present in PE, were able to lower important neuroinflammatory mediators such as NO, IL-6, PGE-2, and TNF- $\alpha$ from lipopolysaccharide (LPS)-stimulated BV-2 microglia. Furthermore, they established the protection of SH-SY5Y and BV-2 (in vitro neuronal models) cell viability by hampering apoptosis and caspase 3/7 and 9 released from $\mathrm{H}_{2} \mathrm{O}_{2}$-induced oxidative stress [158].

Subsequently, Velagapudi et al. delved into urolithin mechanism of action by assessing not only the decrease of the previously mentioned mediators (IL-6, TNF- $\alpha, \mathrm{NO}$ ) but underlining the relation between inhibition of neuroinflammation and Sirt-1 activation in BV2 microglia. Indeed, SIRT-1 levels, after treatment with 5 and $10 \mu \mathrm{M}$ of urolithin, were much higher than control. This could suggest that this compound should activate SIRT-1 in order to perform its neuroprotective activity effect [159].

More recently, Cásedas et al. confirmed these evidences toward another in vitro model, neuro-2a cells, by inducing oxidative stress. Data outlined that urolithin was able to improve mitochondrial activity (MTT assay), redox state (ROS formation, lipid peroxidation), and the activity of antioxidant enzymes (CAT: catalase, SOD: superoxide dismutase, GR: glutathione reductase, GPx: glutathione peroxidase). Furthermore, it raised the cytoprotective peroxiredoxin 1 and 3 expression and it was assessed to be a radical scavenger through ORAC (oxygen radical absorbance capacity) and DPPH assays [160].

Urolithin, contained in pomegranate juice, proved to also be effective in a rat model of Parkinson's disease induced by rotenone. Indeed, the nutritional supplementation with pomegranate juice enhanced postural stability, impeded oxidative damage and $\alpha$-synuclein aggregation, permitted neuronal survival, improved mitochondrial aldehyde dehydrogenase activity, and preserved antiapoptotic Bcl-xL protein at the control level [161].

A recent clinical trial demonstrated the beneficial effects on memory derived from the daily consumption of pomegranate juice. In fact, for a period of 12 months, the diet of two hundred and sixty-one patients (aged $50-75 \mathrm{y})$ has been implemented with pomegranate juice $(8 \mathrm{oz}(236.5 \mathrm{~mL})$ per day) or a placebo drink ( $8 \mathrm{oz}$, matched constituents of pomegranate juice except for pomegranate polyphenols). At six and 12 months, the memory measures (Brief Visuospatial Memory Test-Revised (BVMT-R) and Buschke Selective Reminding Test (SRT)) were carried out. From the results obtained, Siddarth et al. corroborated the hypothesis that the steady consumption of pomegranate juice may stabilize the ability to learn visual information over a 12-month period [162].

Taken together, reported data corroborate the concept that pomegranate may be considered a neuroprotector and developed as an agent for treating neurodegenerative diseases.

\section{Toxicological Aspects of Pomegranate and Potential Interaction with Drugs}

Recently, some research has shown that pomegranate fruit can be considered part of a healthy diet and lifestyle without any risks or side effects [5]. Studies have shown that two doses of pomegranate extract ( 0.4 and $1.2 \mathrm{mg} / \mathrm{kg}$ body weight) produced no toxic reactions in rats in terms of food intake, weight changes, or behavioral or biochemical factors [163].

Heber et al. [164] carried out studies on 64 overweight subjects to assess the safety of the use of extracts in humans. Following the intake of 710 and $1420 \mathrm{mg}$ capsules (containing 435 and $870 \mathrm{mg}$ gallic acid equivalents, respectively), no adverse events occurred and no substantial differences in toxicity were estimated in any subject studied.

Other studies have been carried out on patients with carotid artery stenosis, showing that the intake of pomegranate juice (121 mg/L ellagic acid equivalent) for more than 3 years did not cause any toxic effect on blood parameters or liver, kidney, or heart functions [165]. 
Based on current research on pomegranate, considering its beneficial effects in cancer, cardiovascular diseases, etc., it was interesting to define the effects of pomegranate extracts on the cytochrome P450-3A, a liver enzyme system responsible for the metabolism of several drugs [7].

Studies in rats show that the administration of pomegranate juice possesses an inhibitory activity on the pharmacokinetics of carbamazepine, an anticonvulsant drug also substrate by the cytochrome P450-3A [7].

A single-dose randomized trial in healthy volunteers showed that treatment with pomegranate juice had no effect on the half-life or distribution time of intravenous administration of benzodiazepines with anxiolytic, hypnotic, anticonvulsant, and muscle relaxant properties, and no effect on maximum concentration or clearance after oral administration [7].

All of these findings strengthen the pomegranate value, making it an interesting and safe nutraceutical.

\section{Conclusions}

Today, it is well known that the positive effects of fruit and vegetables in preventing disorders depend on the composition of the bioactive compounds they contain (Table 1) [5,7,166-171].

Table 1. Bioactive compounds present in pomegranate that have been demonstrated to have biological activity.

$\begin{gathered}\text { Bibliographic } \\ \text { Reference }\end{gathered}$
Activity


Table 1. Cont.

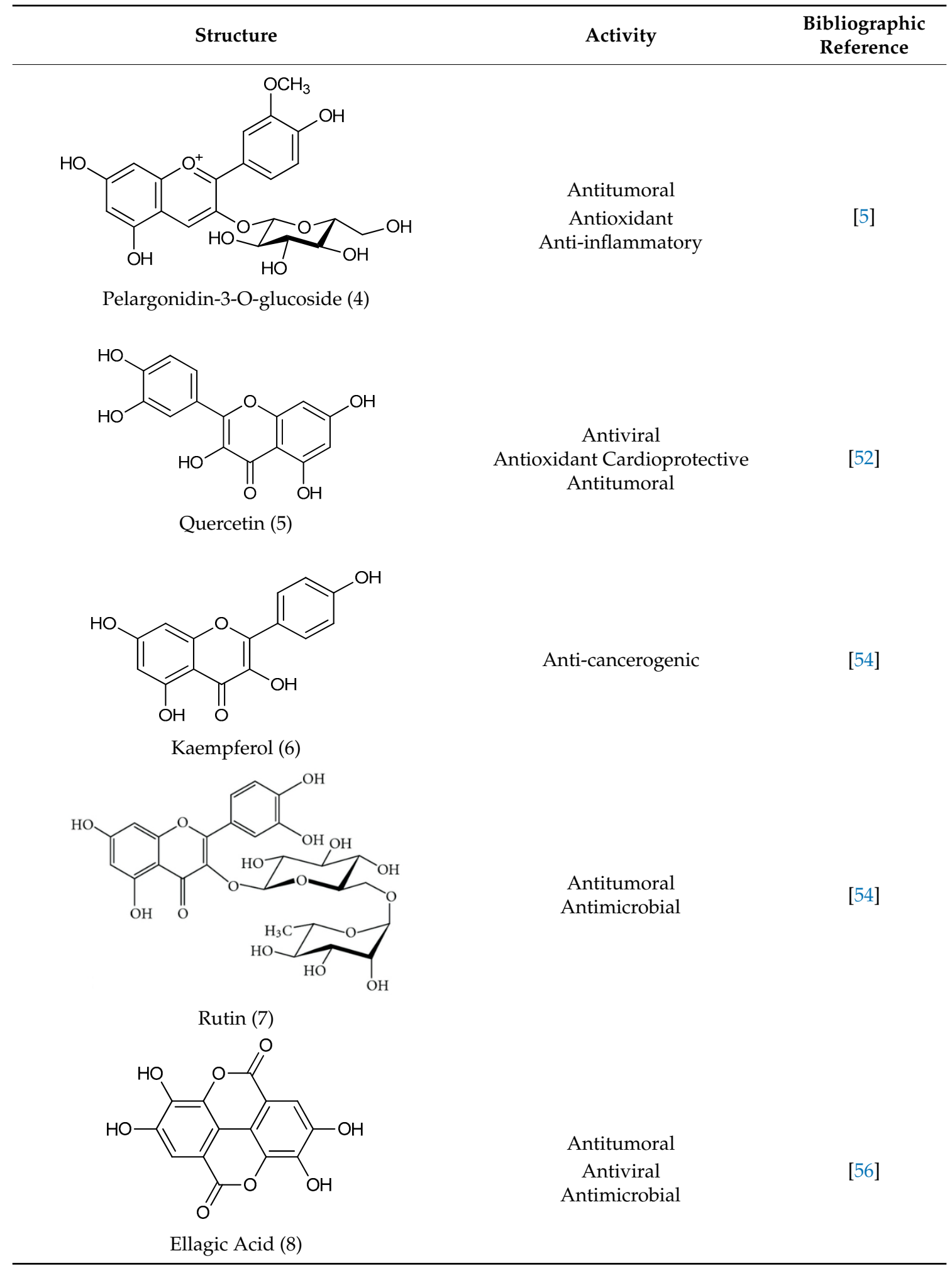


Table 1. Cont.

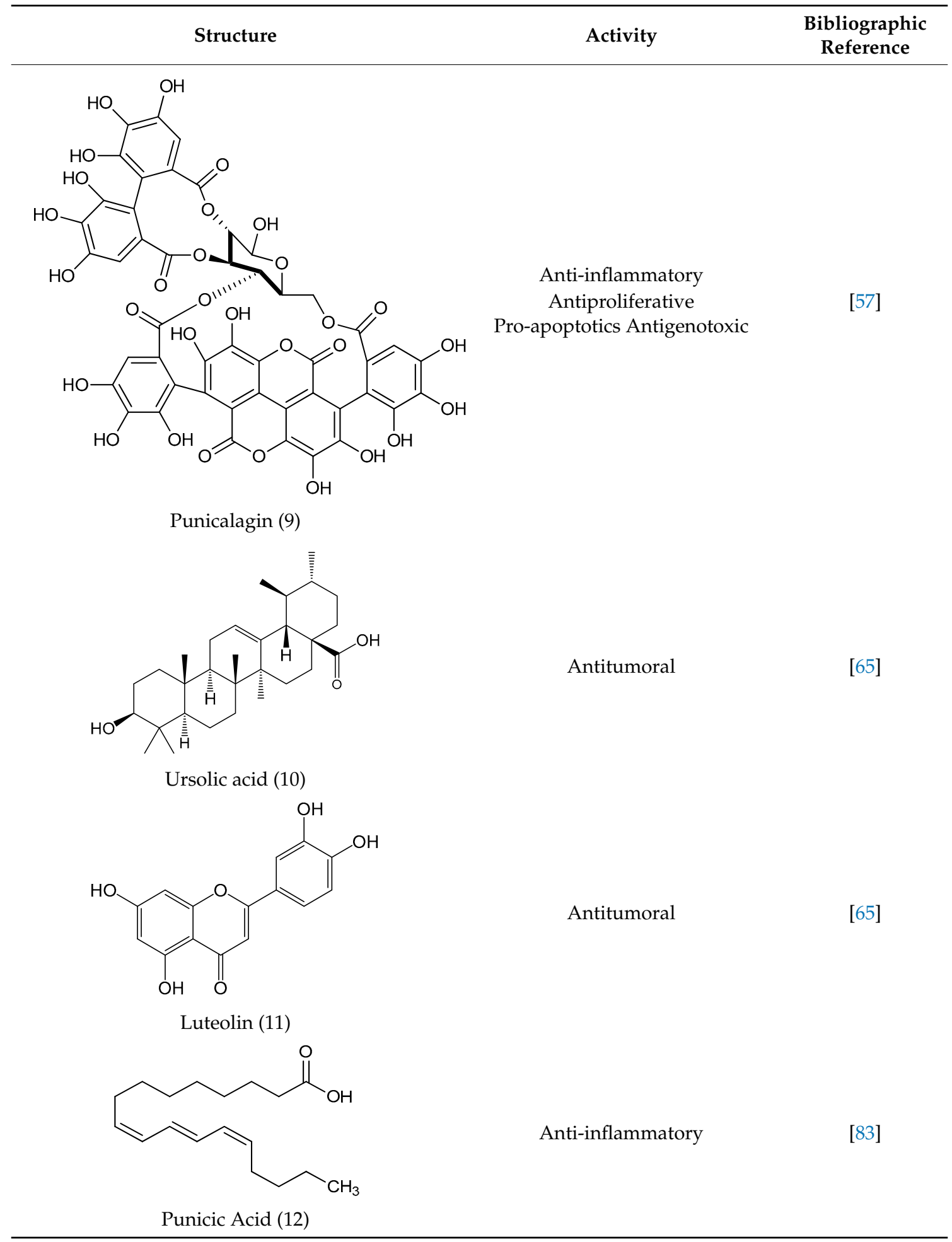


Table 1. Cont.

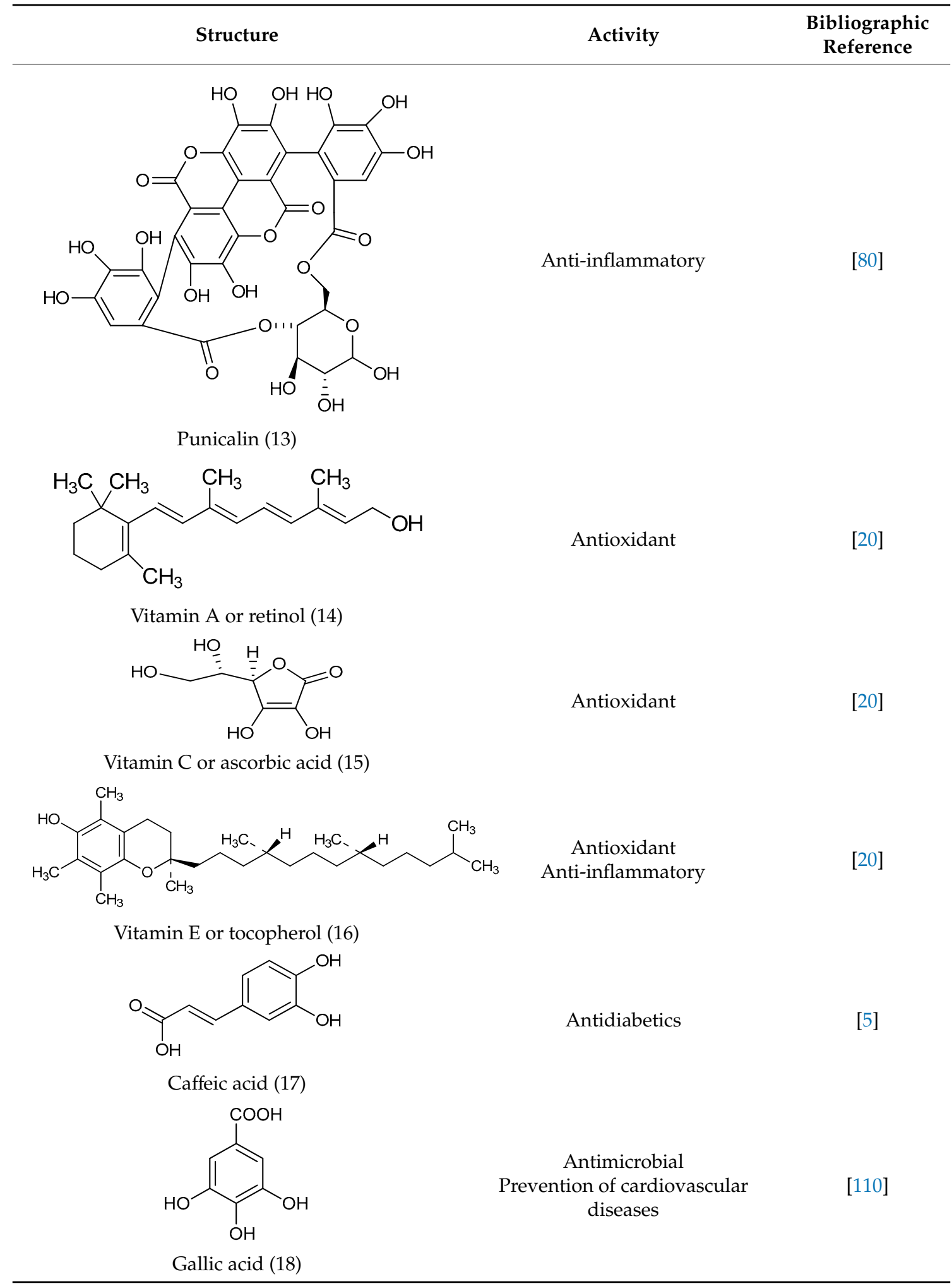

In particular, among them, pomegranate emerges, as well as nutritional resources, for its extensively documented health properties in several application fields (neoplastic, cardiovascular, viral, inflammatory, etc.) that make it a promising tool in medicinal treatments (Table 2). 
Table 2. Biological properties of different pomegranate extracts.

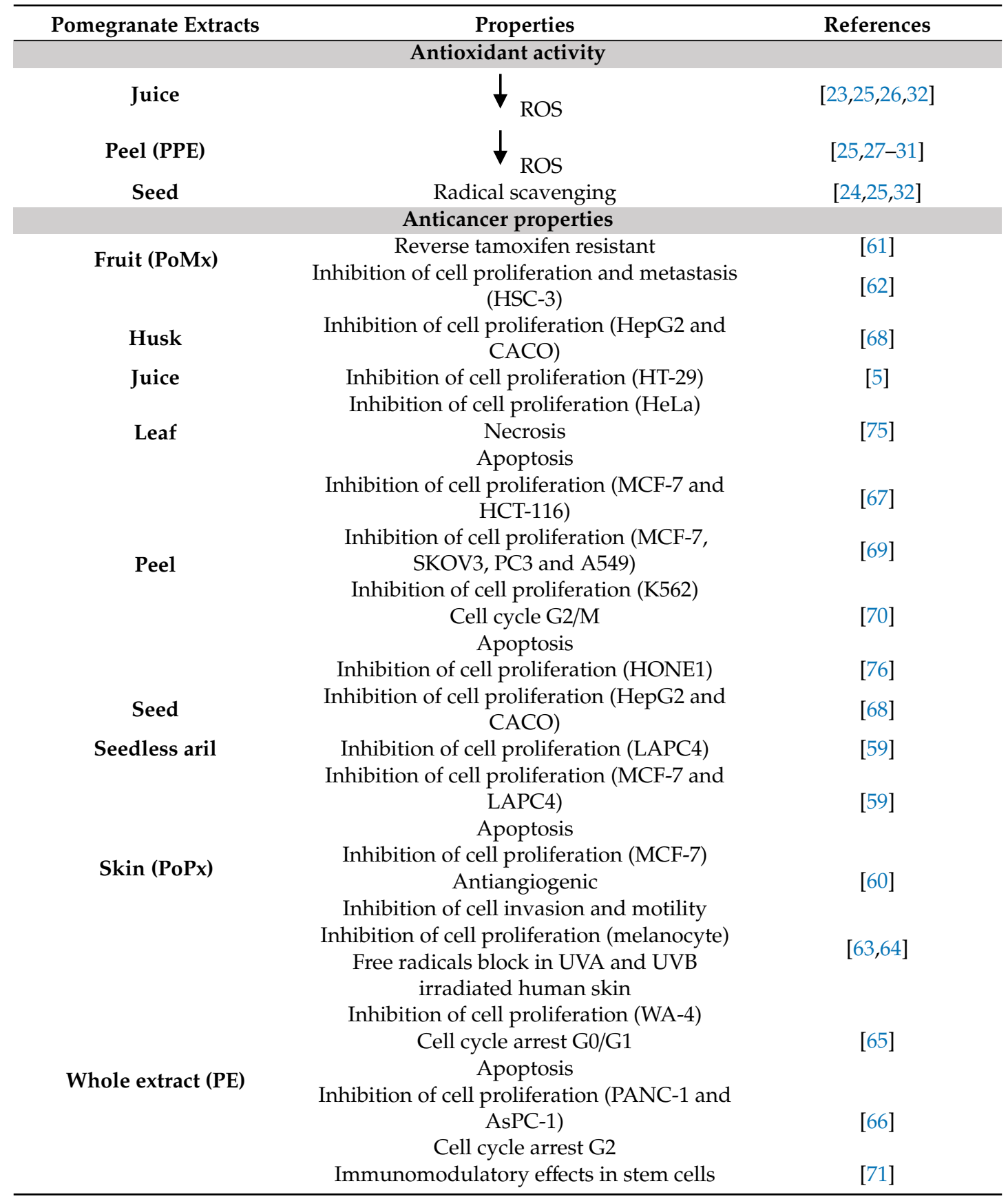


Table 2. Cont.

\begin{tabular}{|c|c|c|}
\hline Pomegranate Extracts & Properties & References \\
\hline \multicolumn{3}{|c|}{ Anti-inflammatory properties } \\
\hline Flower (PFE) & $\begin{array}{l}\text { NO, iNOS, COX-2, PGE-2, TNF- } \alpha \text {, IL-6, } \\
\text { IL-1 } \beta \\
\text { Inhibition of NF-kB activation and MAPKs } \\
\text { phosphorylation }\end{array}$ & [89] \\
\hline Fruit (PoMx) & Thrombospondin, TGF- $\beta 1$ & [85] \\
\hline Peel (PPE) & TNF- $\alpha$, IL- $1 \beta$, MCP- 1, ICAM & [88] \\
\hline Seed & $\begin{array}{c}\downarrow \text { COX, LOX } \\
\downarrow \\
\text { Lipid peroxidation }(\mathrm{LPO})\end{array}$ & {$[81,82]$} \\
\hline Whole extract (PE) & $\downarrow \begin{array}{l}\downarrow \text { NO } \\
\text { COX-2, PTGES }\end{array}$ & {$[80,84]$} \\
\hline \multicolumn{3}{|c|}{ Antidiabetic activity } \\
\hline & $\begin{array}{l}\text { Suppression of } \alpha \text {-glucosidase activity } \\
\text { Activation of PPAR- } \gamma\end{array}$ & $\begin{array}{c}{[95]} \\
{[5]}\end{array}$ \\
\hline Flower (PFE) & $\downarrow_{\mathrm{LPO}}$ & [100] \\
\hline & $\begin{array}{l}\text { Improvement of insulin sensitivity, blood } \\
\text { lipid profile, and liver glycogen content }\end{array}$ & [102] \\
\hline Fruit (PoMx) & $\downarrow_{\text {IRS-1, Akt, GLUT-2, GLUT-4 }}^{\downarrow}$ & $\begin{array}{l}{[99]} \\
{[103]}\end{array}$ \\
\hline Juice & $\begin{array}{l}\text { Inhibition of DPP-4 } \\
\downarrow_{\text {Erythropoietin }}\end{array}$ & $\begin{array}{l}{[104]} \\
{[105]}\end{array}$ \\
\hline Peel (PPE) & $\downarrow \begin{array}{c}\text { Inhibition of LPO } \\
\text { Serum glucose concentration }\end{array}$ & [98] \\
\hline Seed & Improvement of insulin sensitivity & [97] \\
\hline \multicolumn{3}{|c|}{ Antimicrobial activities } \\
\hline & $\begin{array}{l}\text { S. Enteritidis, S. Kentucky } \\
\text { C. albicans, C. parapsilosis, R. mucillaginosa, }\end{array}$ & {$[111]$} \\
\hline Peel (PPE) & $\begin{array}{c}\text { E. dermatitidis, S. aureus } \\
\text { E.coli, P. aeruginisa, P. vulgaris, S. typhi, } \\
\text { S. aureus, S. epidermidis, K. pneumonia }\end{array}$ & [113] \\
\hline Skin (PoPx) & S. aureus, E. coli, Y. enterocolitica & [110] \\
\hline \multicolumn{3}{|c|}{ Prevention of cardiovascular diseases } \\
\hline Peel (PPE) & $\begin{array}{c}\uparrow \text { Erythrocyte count, bleeding time, } \\
\text { thrombin time } \\
\text { Activation of thromboplastin time } \\
\text { Inhibition of platelets aggregation induced by } \\
\text { ADP } \\
\text { Positive effects on angina pectoris } \\
\text { Improvement of lipid profile, oxidative, } \\
\text { and inflammatory biomarkers } \\
\square \text { Blood pressure } \\
\text { Reduction of doxorubicin cardiotoxicity }\end{array}$ & $\begin{array}{c}{[119]} \\
{[121]} \\
{[121,122]} \\
{[120]}\end{array}$ \\
\hline
\end{tabular}


Table 2. Cont.

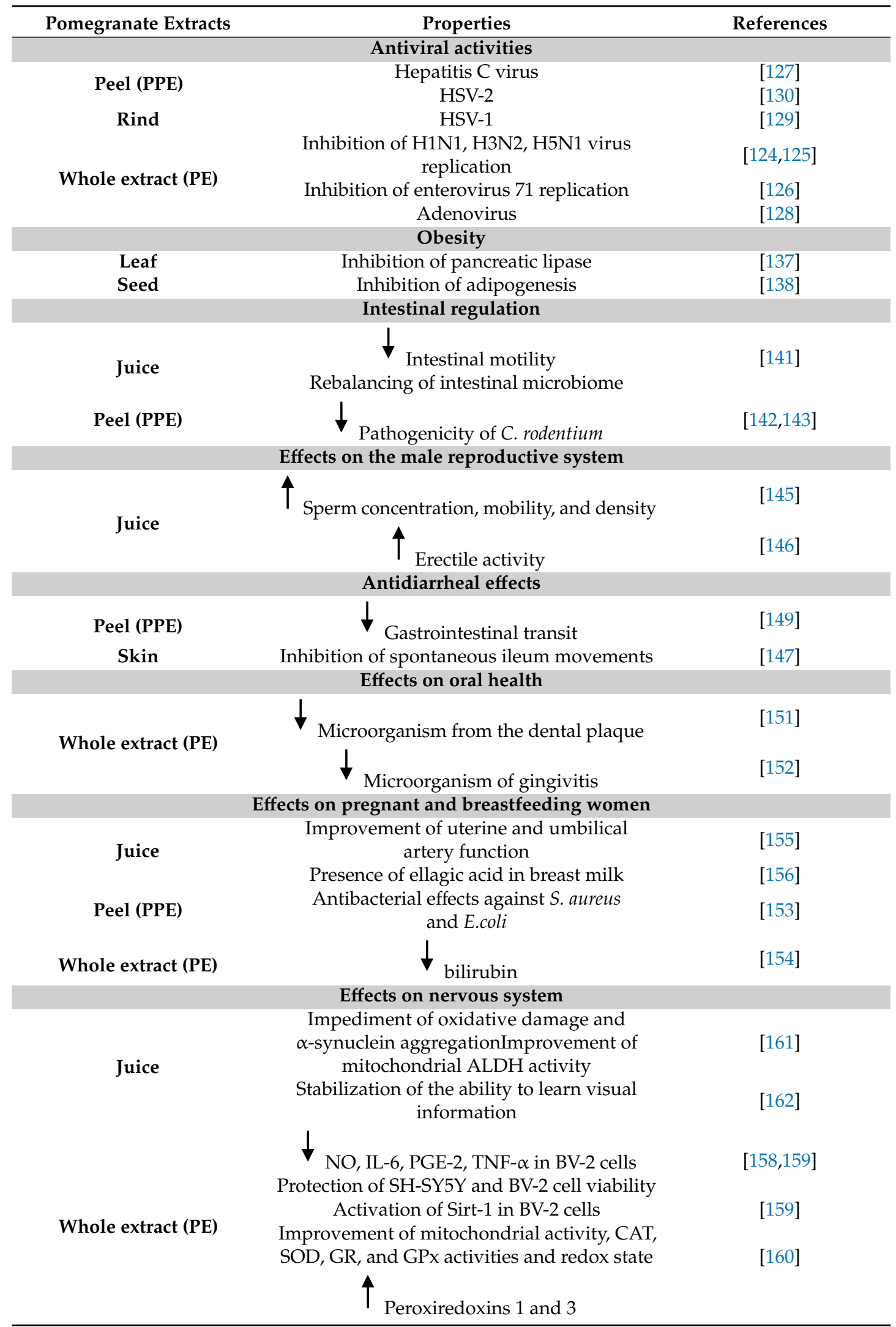


Certainly, the juice is the most widespread type of pomegranate-based product in stores for its ease of consumption, followed by capsules with a concentration of ellagic acid of $40 \%$ [3]. From what emerges from the various studies analyzed, the interest in the consumption and production of pomegranate has greatly increased in recent years [172-175].

Indeed, prior research has thoroughly supported the beneficial effects of pomegranate regarding not only the phytocomplex, but also the single components, among which the various tannins and the ellagic acid stand out. However, several studies stated that the synergistic potential of all pomegranate components (for example phenolic compounds) is powerful to that of single constituents [176-178]. Precisely, the latter has recently aroused great interest for the potential inhibitory activity against Sars-CoV-2, demonstrated through docking studies and, for this reason, it seems clear that continuing the research with the evaluation of the activity could represent an important goal for the fight against this plague [131,133].

Moreover, much research has promoted the possible employment of pomegranate together with other drugs already available (like doxorubicin), establishing its good influence in reverting their chemoresistance, thus overcoming their limits, lowering the toxicity, and increasing the action.

In light of the reasons mentioned above, it becomes evident that pomegranate turns out to be one of the most attractive nutraceuticals, and the deepening of its study could lead to the opening of new avenues for medical science domains.

Author Contributions: Conceptualization, A.C. (Anna Caruso) and A.B.; methodology, D.I.; software, J.C.; validation, A.F. and C.F.; resources, A.T. and G.B.; data curation, A.C. (Alessia Catalano); writing-original draft preparation, A.C. (Anna Caruso) and A.B.; writing-review and editing, A.C. (Alessia Carocci) and D.I.; supervision, M.S.S. All authors have read and agreed to the published version of the manuscript.

Funding: This research received no external funding

Conflicts of Interest: The authors declare no conflict of interest.

\section{References}

1. Bellini, E.; Giordani, E.; La Malfa, S. Minor fruit tree species in Italy, a traditional resource for in the innavation of fruitculture: Persimmon and pomegranate as study cases. Italus Hortus 2010, 17, 75-90.

2. Sepulveda, E.L.G.; Sàenz, C.; Tapia, M. Minimal processing of pomegranate var. wonderful. In Proceedings of the Production, Processing and Marketing of Pomegranate in the Mediterranean Region: Advances in Research and Technology, Universidad Miguel Hernández (EPSO-UMH), Orihuela, Spain, 15-17 October 1998; pp. 237-242.

3. Da Silva, J.A.T.; Rana, T.S.; Narzary, D.; Verma, N.; Meshram, D.T.; Ranade, S.A. Pomegranate biology and biotechnology: A review. Sci. Hortic. 2013, 160, 85-107. [CrossRef]

4. Heber, D.; Schulman, R.N.; Seeram, N.P. Pomegranates: Ancient Roots to Modern Medicine; CRC Press: Boca Raton, FL, USA, 2006; p. 262.

5. Viuda-Martos, M.; Fernandez-Lopez, J.; Perez-Alvarez, J.A. Pomegranate and its Many Functional Components as Related to Human Health: A Review. Compr. Rev. Food Sci. Food Saf. 2010, 9, 635-654. [CrossRef]

6. Andreu-Sevilla, A.J.; Signes-Pastor, A.J.; Carbonell-Barrachina, A.A. La Granada Y Su Zumo. Producción, Composición Y Propiedades Beneficiosas Para La Salud. Inf. Univ. Miguel Hernández Elchedigital 2008, 234, 36-39.

7. Jurenka, J.S. Therapeutic applications of pomegranate (Punica granatum L.): A review. Altern. Med. Rev. 2008, $13,128-144$.

8. Ismail, T.; Sestili, P.; Akhtar, S. Pomegranate peel and fruit extracts: A review of potential anti-inflammatory and anti-infective effects. J. Ethnopharmacol. 2012, 143, 397-405. [CrossRef]

9. Cano, A.; Arnao, M.B. Hydrophilic and lipophilic antioxidant activity in different leaves of three lettuce varieties. Int. J. Food Prop. 2005, 8, 521-528. [CrossRef] 
10. Plastina, P.; Apriantini, A.; Meijerink, J.; Witkamp, R.; Gabriele, B.; Fazio, A. In Vitro Anti-Inflammatory and Radical Scavenging Properties of Chinotto (Citrus myrtifolia Raf.) Essential Oils. Nutrients 2018, 10, 783. [CrossRef]

11. Chen, M.L.; Vigneault, C.; Raghavan, G.S.V.; Kubow, S. Importance of phytochemical content of fruits and vegetables to human health. Stewart Postharvest Rev. 2007, 3, 20-32.

12. Badria, F.A.; Zidan, O.A. Natural products for dental caries prevention. J. Med. Food 2004, 7, 381-384. [CrossRef]

13. Parisi, O.I.; Casaburi, I.; Sinicropi, M.S.; Avena, P.; Caruso, A.; Givigliano, F.; Pezzi, V.; Puoci, F. Most Relevant Polyphenols Present in the Mediterranean Diet and Their Incidence in Cancer Diseases. In Polyphenols in Human Health and Disease; Watson, R.R., Preedy, V.R., Zibadi, S., Eds.; Academic Press: Cambridge, MA, USA, 2014; Volume 2, pp. 1341-1351.

14. Plastina, P.; Fazio, A.; Gabriele, B. Comparison of fatty acid profile and antioxidant potential of extracts of seven Citrus rootstock seeds. Nat. Prod. Res. 2012, 26, 2182-2187. [CrossRef] [PubMed]

15. Leporini, M.; Loizzo, M.R.; Tundis, R.; La Torre, C.; Fazio, A.; Plastina, P. Non-Pungent n-3 Polyunsaturated Fatty Acid (PUFA)-Derived Capsaicin Analogues as Potential Functional Ingredients with Antioxidant and Carbohydrate-Hydrolysing Enzyme Inhibitory Activities. Antioxidants 2019, 8, 162. [CrossRef] [PubMed]

16. Benincasa, C.; La Torre, C.; Plastina, P.; Fazio, A.; Perri, E.; Caroleo, M.C.; Gallelli, L.; Cannataro, R.; Cione, E. Hydroxytyrosyl Oleate: Improved Extraction Procedure from Olive Oil and By-Products, and In Vitro Antioxidant and Skin Regenerative Properties. Antioxidants 2019, 8, 233. [CrossRef] [PubMed]

17. Gabriele, B.; Fazio, A.; Carchedi, M.; Plastina, P. In vitro antioxidant activity of extracts of Sybaris liquorice roots from Southern Italy. Nat. Prod. Res. 2012, 26, 2176-2181. [CrossRef]

18. Cannataro, R.; Caroleo, M.C.; Fazio, A.; La Torre, C.; Plastina, P.; Gallelli, L.; Lauria, G.; Cione, E. Ketogenic Diet and microRNAs Linked to Antioxidant Biochemical Homeostasis. Antioxidants 2019, 8, 269. [CrossRef]

19. Espin, J.C.; Garcia-Conesa, M.T.; Tomas-Barberan, F.A. Nutraceuticals: Facts and fiction. Phytochemistry 2007, 68, 2986-3008. [CrossRef]

20. Hounsome, N.; Hounsome, B.; Tomos, D.; Edwards-Jones, G. Plant metabolites and nutritional quality of vegetables. J. Food Sci. 2008, 73, R48-R65. [CrossRef]

21. Dorais, M.; Ehret, D.L.; Papadopoulos, A.P. Tomato (Solanum lycopersicum) health components: From the seed to the consumer. Phytochem. Rev. 2008, 7, 231-250. [CrossRef]

22. Amarowicz, R.; Pegg, R.B.; Rahimi-Moghaddam, P.; Barl, B.; Weil, J.A. Free-radical scavenging capacity and antioxidant activity of selected plant species from the Canadian prairies. Food Chem. 2004, 84, 551-562. [CrossRef]

23. Gil, M.I.; Tomas-Barberan, F.A.; Hess-Pierce, B.; Holcroft, D.M.; Kader, A.A. Antioxidant activity of pomegranate juice and its relationship with phenolic composition and processing. J. Agric. Food Chem. 2000, 48, 4581-4589. [CrossRef]

24. Basiri, S. Evaluation of antioxidant and antiradical properties of Pomegranate (Punica granatum L.) seed and defatted seed extracts. J. Food Sci. Technol. 2015, 52, 1117-1123. [CrossRef] [PubMed]

25. Derakhshan, Z.; Ferrante, M.; Tadi, M.; Ansari, F.; Heydari, A.; Hosseini, M.S.; Conti, G.O.; Sadrabad, E.K. Antioxidant activity and total phenolic content of ethanolic extract of pomegranate peels, juice and seeds. Food Chem. Toxicol. 2018, 114, 108-111. [CrossRef] [PubMed]

26. Di Stefano, V.; Pitonzo, R.; Novara, M.E.; Bongiorno, D.; Indelicato, S.; Gentile, C.; Avellone, G.; Bognanni, R.; Scandurra, S.; Melilli, M.G. Antioxidant activity and phenolic composition in pomegranate (Punica granatum L.) genotypes from south Italy by UHPLC-Orbitrap-MS approach. J. Sci. Food Agric. 2019, 99, 1038-1045. [CrossRef]

27. Mastrogiovanni, F.; Bernini, R.; Basirico, L.; Bernabucci, U.; Campo, M.; Romani, A.; Santi, L.; Lacetera, N. Antioxidant and anti-inflammatory effects of pomegranate peel extracts on bovine mammary epithelial cells BME-UV1. Nat. Prod. Res. 2020, 34, 1465-1469. [CrossRef] [PubMed]

28. Nur Hanani, Z.A.; Cheng Yee, F.; Nor-Khaizura, M.A.R. Effect of pomegranate (Punica granatum L.) peel powder on the antioxidant and antimicrobial properties of fish gelatin films as active packaging. Food Hydrocoll. 2019, 89, 253-259. [CrossRef] 
29. Bertolo, M.R.V.; Martins, V.C.A.; Horn, M.M.; Brenelli, L.B.; Plepis, A.M.G. Rheological and antioxidant properties of chitosan/gelatin-based materials functionalized by pomegranate peel extract. Carbohydr. Polym. 2020, 228, 115386. [CrossRef]

30. Jalal, H.; Pal, M.A.; Ahmad, S.R.; Rather, M.; Andrabi, M.; Hamdani, S. Physico-chemical and functional properties of pomegranate peel and seed powder. Pharm. Innov. J. 2018, 7, 1127-1131.

31. Surek, E.; Nilufer-Erdil, D. Phenolic contents, antioxidant activities and potential bioaccessibilities of industrial pomegranate nectar processing wastes. Int. J. Food Sci. Technol. 2016, 51, 231-239. [CrossRef]

32. Pinilla, M.; Iglesias-Moya, J.; Jesús Campos, M.; Corpas, F.J.; Palma, J.M. Pomegranate (Punica granatum L.) Fruits: Characterization of the Main Enzymatic Antioxidants (Peroxisomal Catalase and SOD Isozymes) and the NADPH-Regenerating System. Agronomy 2019, 9, 338. [CrossRef]

33. Ferlay, J.; Shin, H.R.; Bray, F.; Forman, D.; Mathers, C.; Parkin, D.M. Estimates of worldwide burden of cancer in 2008: GLOBOCAN 2008. Int. J. Cancer 2010, 127, 2893-2917. [CrossRef]

34. Saturnino, C.; Caruso, A.; Iacopetta, D.; Rosano, C.; Ceramella, J.; Muia, N.; Mariconda, A.; Bonomo, M.G.; Ponassi, M.; Rosace, G.; et al. Inhibition of Human Topoisomerase II by N,N,N-Trimethylethanammonium Iodide Alkylcarbazole Derivatives. Chem. Med. Chem. 2018, 13, 2635-2643. [CrossRef] [PubMed]

35. Saturnino, C.; Caruso, A.; Longo, P.; Capasso, A.; Pingitore, A.; Caroleo, M.C.; Cione, E.; Perri, M.; Nicolo, F.; Nardo, V.M.; et al. Crystallographic study and biological evaluation of 1,4-dimethyl-N-alkylcarbazoles. Curr. Top. Med. Chem. 2015, 15, 973-979. [CrossRef]

36. Chimento, A.; Sala, M.; Gomez-Monterrey, I.M.; Musella, S.; Bertamino, A.; Caruso, A.; Sinicropi, M.S.; Sirianni, R.; Puoci, F.; Parisi, O.I.; et al. Biological activity of 3-chloro-azetidin-2-one derivatives having interesting antiproliferative activity on human breast cancer cell lines. Bioorganic Med. Chem. Lett. 2013, 23, 6401-6405. [CrossRef] [PubMed]

37. Kawanishi, S.; Hiraku, Y.; Pinlaor, S.; Ma, N. Oxidative and nitrative DNA damage in animals and patients with inflammatory diseases in relation to inflammation-related carcinogenesis. Biol. Chem. 2006, 387, 365-372. [CrossRef] [PubMed]

38. Ishikawa, K.; Takenaga, K.; Akimoto, M.; Koshikawa, N.; Yamaguchi, A.; Imanishi, H.; Nakada, K.; Honma, Y.; Hayashi, J. ROS-generating mitochondrial DNA mutations can regulate tumor cell metastasis. Science 2008, 320, 661-664. [CrossRef]

39. Caruso, A.; Iacopetta, D.; Puoci, F.; Cappello, A.R.; Saturnino, C.; Sinicropi, M.S. Carbazole derivatives: A promising scenario for breast cancer treatment. Mini Rev. Med. Chem. 2016, 16, 630-643. [CrossRef]

40. Ceramella, J.; Caruso, A.; Occhiuzzi, M.A.; Iacopetta, D.; Barbarossa, A.; Rizzuti, B.; Dallemagne, P.; Rault, S.; El-Kashef, H.; Saturnino, C.; et al. Benzothienoquinazolinones as new multi-target scaffolds: Dual inhibition of human Topoisomerase I and tubulin polymerization. Eur. J. Med. Chem. 2019, 181, 111583. [CrossRef]

41. Sinicropi, M.S.; Iacopetta, D.; Rosano, C.; Randino, R.; Caruso, A.; Saturnino, C.; Muia, N.; Ceramella, J.; Puoci, F.; Rodriquez, M.; et al. N-thioalkylcarbazoles derivatives as new anti-proliferative agents: Synthesis, characterisation and molecular mechanism evaluation. J. Enzyme Inhib. Med. Chem. 2018, 33, 434-444. [CrossRef]

42. Faienza, M.F.; Corbo, F.; Carocci, A.; Catalano, A.; Clodoveo, M.L.; Grano, M.; Wang, D.Q.-H.; D'Amato, G.; Muraglia, M.; Franchini, C.; et al. Novel insights in health-promoting properties of sweet cherries. J. Funct. Foods 2020, 69, 103945. [CrossRef]

43. Karaaslan, M.; Vardin, H.; Varliklioz, S.; Yilmaz, F.M. Antiproliferative and antioxidant activities of Turkish pomegranate (Punica granatum L.) accessions. Int. J. Food Sci. Technol. 2014, 49, 82-90. [CrossRef]

44. Aqil, F.; Munagala, R.; Vadhanam, M.V.; Kausar, H.; Jeyabalan, J.; Schultz, D.J.; Gupta, R.C. Anti-proliferative activity and protection against oxidative DNA damage by punicalagin isolated from pomegranate husk. Food Res. Int. 2012, 49, 345-353. [CrossRef] [PubMed]

45. Dikmen, M.; Ozturk, N.; Ozturk, Y. The antioxidant potency of Punica granatum L. Fruit peel reduces cell proliferation and induces apoptosis on breast cancer. J. Med. Food 2011, 14, 1638-1646. [CrossRef] [PubMed]

46. Lansky, E.P.; Jiang, W.; Mo, H.; Bravo, L.; Froom, P.; Yu, W.; Harris, N.M.; Neeman, I.; Campbell, M.J. Possible synergistic prostate cancer suppression by anatomically discrete pomegranate fractions. Investig. New Drugs 2005, 23, 11-20. [CrossRef] [PubMed] 
47. Fazio, A.; Iacopetta, D.; La Torre, C.; Ceramella, J.; Muia, N.; Catalano, A.; Carocci, A.; Sinicropi, M.S. Finding solutions for agricultural wastes: Antioxidant and antitumor properties of pomegranate Akko peel extracts and beta-glucan recovery. Food Funct. 2018, 9, 6618-6631. [CrossRef] [PubMed]

48. Hong, M.Y.; Seeram, N.P.; Heber, D. Pomegranate polyphenols down-regulate expression of androgen-synthesizing genes in human prostate cancer cells overexpressing the androgen receptor. J. Nutr. Biochem. 2008, 19, 848-855. [CrossRef]

49. Di Carlo, G.; Mascolo, N.; Izzo, A.A.; Capasso, F. Flavonoids: Old and new aspects of a class of natural therapeutic drugs. Life Sci. 1999, 65, 337-353. [CrossRef]

50. Noda, Y.; Kaneyuki, T.; Mori, A.; Packer, L. Antioxidant activities of pomegranate fruit extract and its anthocyanidins: Delphinidin, cyanidin, and pelargonidin. J. Agric. Food Chem. 2002, 50, 166-171. [CrossRef]

51. Iacopetta, D.; Grande, F.; Caruso, A.; Mordocco, R.A.; Plutino, M.R.; Scrivano, L.; Ceramella, J.; Muia, N.; Saturnino, C.; Puoci, F.; et al. New insights for the use of quercetin analogs in cancer treatment. Future Med. Chem. 2017, 9, 2011-2028. [CrossRef]

52. Levin, G.M. Pomegranate Roads: A Soviet Botanist's Exile from Eden; Floreant Press: Forestville, CA, USA, 2006.

53. Grande, F.; Parisi, O.I.; Mordocco, R.A.; Rocca, C.; Puoci, F.; Scrivano, L.; Quintieri, A.M.; Cantafio, P.; Ferla, S.; Brancale, A.; et al. Quercetin derivatives as novel antihypertensive agents: Synthesis and physiological characterization. Eur. J. Pharm. Sci. 2016, 82, 161-170. [CrossRef]

54. Van Elswijk, D.A.; Schobel, U.P.; Lansky, E.P.; Irth, H.; van der Greef, J. Rapid dereplication of estrogenic compounds in pomegranate (Punica granatum) using on-line biochemical detection coupled to mass spectrometry. Phytochemistry 2004, 65, 233-241. [CrossRef]

55. Khatib, M. Bioactive Compounds into Edible Syrian Plants: Pomegranate and Capper; University of Florence: Florence, Italy, 2015.

56. Gonzalez-Sarrias, A.; Espin, J.C.; Tomas-Barberan, F.A.; Garcia-Conesa, M.T. Gene expression, cell cycle arrest and MAPK signalling regulation in Caco-2 cells exposed to ellagic acid and its metabolites, urolithins. Mol. Nutr. Food Res. 2009, 53, 686-698. [CrossRef] [PubMed]

57. Adams, L.S.; Seeram, N.P.; Aggarwal, B.B.; Takada, Y.; Sand, D.; Heber, D. Pomegranate juice, total pomegranate ellagitannins, and punicalagin suppress inflammatory cell signaling in colon cancer cells. J. Agric. Food Chem. 2006, 54, 980-985. [CrossRef] [PubMed]

58. Pantuck, A.J.; Leppert, J.T.; Zomorodian, N.; Aronson, W.; Hong, J.; Barnard, R.J.; Seeram, N.; Liker, H.; Wang, H.; Elashoff, R.; et al. Phase II study of pomegranate juice for men with rising prostate-specific antigen following surgery or radiation for prostate cancer. Clin. Cancer Res. 2006, 12, 4018-4026. [CrossRef] [PubMed]

59. Koyama, S.; Cobb, L.J.; Mehta, H.H.; Seeram, N.P.; Heber, D.; Pantuck, A.J.; Cohen, P. Pomegranate extract induces apoptosis in human prostate cancer cells by modulation of the IGF-IGFBP axis. Growth Horm. IGF Res. 2010, 20, 55-62. [CrossRef]

60. Khan, G.N.; Gorin, M.A.; Rosenthal, D.; Pan, Q.; Bao, L.W.; Wu, Z.F.; Newman, R.A.; Pawlus, A.D.; Yang, P.; Lansky, E.P.; et al. Pomegranate fruit extract impairs invasion and motility in human breast cancer. Integr. Cancer Ther. 2009, 8, 242-253. [CrossRef]

61. Aiyer, H.S.; Bouker, K.B.; Cook, K.L.; Facey, C.O.; Hu, R.; Schwartz, J.L.; Shajahan, A.N.; Hilakivi-Clarke, L.; Clarke, R. Interaction of dietary polyphenols with molecular signaling pathways of antiestrogen resistance: Possible role in breast cancer recurrence. Horm. Mol. Biol. Clin. Investig. 2012, 9, 127-141. [CrossRef]

62. Peng, S.Y.; Hsiao, C.C.; Lan, T.H.; Yen, C.Y.; Farooqi, A.A.; Cheng, C.M.; Tang, J.Y.; Yu, T.J.; Yeh, Y.C.; Chuang, Y.T.; et al. Pomegranate extract inhibits migration and invasion of oral cancer cells by downregulating matrix metalloproteinase-2/9 and epithelial-mesenchymal transition. Environ. Toxicol. 2020, 35, 673-682. [CrossRef]

63. Kasai, K.; Yoshimura, M.; Koga, T.; Arii, M.; Kawasaki, S. Effects of oral administration of ellagic acid-rich pomegranate extract on ultraviolet-induced pigmentation in the human skin. J. Nutr. Sci. Vitaminol. 2006, 52, 383-388. [CrossRef]

64. Manasathien, J.; Kupittayanant, S.; Indrapichate, K. Protective Efficacy of Pomegranate (Punica Granatum Linn., Punicaceae) Peel Ethanolic Extract on UVB-Irradiated Rat Skin. Am. Eurasian J. Toxicol. Sci. 2011, 3, 250-258. 
65. Dai, Z.; Nair, V.; Khan, M.; Ciolino, H.P. Pomegranate extract inhibits the proliferation and viability of MMTV-Wnt-1 mouse mammary cancer stem cells in vitro. Oncol. Rep. 2010, 24, 1087-1091.

66. Nair, V.; Dai, Z.; Khan, M.; Ciolino, H.P. Pomegranate extract induces cell cycle arrest and alters cellular phenotype of human pancreatic cancer cells. Anticancer. Res. 2011, 31, 2699-2704.

67. Motaal, A.A.; Shaker, S. Anticancer and Antioxidant Activities of Standardized Whole Fruit, Pulp and Peel Extracts of Egyptian Pomegranate. Open Conf. Proc. J. 2011, 2, 41-45. [CrossRef]

68. El-Awady, M.A.; Awad, N.S.; El-Tarras, A.E. Evaluation of the anticancer activities of pomegranate (Punica granatum) and harmal (Rhazya stricta) plants grown in Saudi Arabia. Int. J. Curr. Microbiol. Appl. Sci. 2015, 4, 1158-1167.

69. Modaeinama, S.; Abasi, M.; Abbasi, M.M.; Jahanban-Esfahlan, R. Anti-Tumoral Properties of Punica Granatum (Pomegranate) Peel Extract on Different Human Cancer Cells. Asian Pac. J. Cancer Prev. 2015, 16, 5697-5701. [CrossRef] [PubMed]

70. Asmaa, M.J.; Ali, A.J.; Farid, J.M.; Azman, S. Growth inhibitory effects of crude pomegranate peel extract on chronic myeloid leukemia, K562 cells. Int. J. Appl. Basic Med. Res. 2015, 5, 100-105. [PubMed]

71. Rostami, Z.; Khorashadizadeh, M.; Ghoncheh, M.; Naseri, M. Effect of Pomegranate Extract in Mesenchymal Stem Cells by Modulation of MicroRNA-155, MicroRNA-21, MicroRNA-23b, MicroRNA-126a, and PI3K $\backslash$ AKT1 $\backslash$ NF-B Expression. DNA Cell Biol. 2020. [CrossRef] [PubMed]

72. Saturnino, C.; Barone, I.; Iacopetta, D.; Mariconda, A.; Sinicropi, M.S.; Rosano, C.; Campana, A.; Catalano, S.; Longo, P.; Ando, S. N-heterocyclic carbene complexes of silver and gold as novel tools against breast cancer progression. Futur. Med. Chem. 2016, 8, 2213-2229. [CrossRef]

73. Chimento, A.; De Amicis, F.; Sirianni, R.; Sinicropi, M.S.; Puoci, F.; Casaburi, I.; Saturnino, C.; Pezzi, V. Progress to Improve Oral Bioavailability and Beneficial Effects of Resveratrol. Int. J. Mol. Sci. 2019, 20, 1381. [CrossRef]

74. Parisi, O.I.; Morelli, C.; Puoci, F.; Saturnino, C.; Caruso, A.; Sisci, D.; Trombino, G.E.; Picci, N.; Sinicropi, M.S. Magnetic molecularly imprinted polymers (MMIPs) for carbazole derivative release in targeted cancer therapy. J. Mater. Chem. B 2014, 2, 6619-6625. [CrossRef]

75. Sarkar, S.; Kotteeswaran, V. Green synthesis of silver nanoparticles from aqueous leaf extract of Pomegranate (Punica granatum) and their anticancer activity on human cervical cancer cells. Adv. Nat. Sci. Nanosci. Nanotechnol. 2018, 9, 025014. [CrossRef]

76. Yusefi, M.; Shameli, K.; Ali, R.R.; Pang, S.W.; Teow, S.Y. Evaluating Anticancer Activity of Plant-Mediated Synthesized Iron Oxide Nanoparticles Using Punica Granatum Fruit Peel Extract. J. Mol. Struct. 2020, 1204, 127539. [CrossRef]

77. Sinicropi, M.S.; Caruso, A.; Conforti, F.; Marrelli, M.; El Kashef, H.; Lancelot, J.C.; Rault, S.; Statti, G.A.; Menichini, F. Synthesis, inhibition of NO production and antiproliferative activities of some indole derivatives. J. Enzyme Inhib. Med. Chem. 2009, 24, 1148-1153. [CrossRef] [PubMed]

78. Saturnino, C.; Popolo, A.; Ramunno, A.; Adesso, S.; Pecoraro, M.; Plutino, M.R.; Rizzato, S.; Albinati, A.; Marzocco, S.; Sala, M.; et al. Anti-Inflammatory, Antioxidant and Crystallographic Studies of N-Palmitoyl-ethanol Amine (PEA) Derivatives. Molecules 2017, 22, 616. [CrossRef] [PubMed]

79. Plastina, P.; Benincasa, C.; Perri, E.; Fazio, A.; Augimeri, G.; Poland, M.; Witkamp, R.; Meijerink, J. Identification of hydroxytyrosyl oleate, a derivative of hydroxytyrosol with anti-inflammatory properties, in olive oil by-products. Food Chem. 2019, 279, 105-113. [CrossRef]

80. Lee, C.J.; Chen, L.G.; Liang, W.L.; Wang, C.C. Anti-inflammatory effects of Punica granatum Linne in vitro and in vivo. Food Chem. 2010, 118, 315-322. [CrossRef]

81. Tomas-Barberan, F.A. Granada y salud: Aspectos farmacologicos y terapéuticos de la Granada. In El Granado-I Jornadas Nacionales Sobre el Granado: Produccion, Economia, Indrustrializacion, Alimentacion y Salud; Moreno, P.M., Garcia, F.H., Murcia, P.L., Eds.; Documentos Poscosecha: Valencia, Spain, 2010; pp. 7-22.

82. Negro, C.; Longo, L.; Vasapollo, G.; De Bellis, L.; Miceli, A. Biochemical, Antioxidant and Anti-Inflammatory Properties of Pomegranate Fruits Growing in Southern Italy (Salento, Apulia). Acta Aliment. 2012, 41, 190-199. [CrossRef] 
83. Boussetta, T.; Raad, H.; Letteron, P.; Gougerot-Pocidalo, M.A.; Marie, J.C.; Driss, F.; El-Benna, J. Punicic acid a conjugated linolenic acid inhibits TNFalpha-induced neutrophil hyperactivation and protects from experimental colon inflammation in rats. PLOS ONE 2009, 4, e6458. [CrossRef]

84. Jung, K.H.; Kim, M.J.; Ha, E.; Uhm, Y.K.; Kim, H.K.; Chung, J.H.; Yim, S.V. Suppressive effect of Punica granatum on the production of tumor necrosis factor (Tnf) in BV2 microglial cells. Biol. Pharm. Bull. 2006, 29, 1258-1261. [CrossRef]

85. De Nigris, F.; Balestrieri, M.L.; Williams-Ignarro, S.; D’Armiento, F.P.; Fiorito, C.; Ignarro, L.J.; Napoli, C. The influence of pomegranate fruit extract in comparison to regular pomegranate juice and seed oil on nitric oxide and arterial function in obese Zucker rats. Nitric Oxide Biol. Chem. 2007, 17, 50-54. [CrossRef]

86. Larrosa, M.; Gonzalez-Sarrias, A.; Yanez-Gascon, M.J.; Selma, M.V.; Azorin-Ortuno, M.; Toti, S.; Tomas-Barberan, F.; Dolara, P.; Espin, J.C. Anti-inflammatory properties of a pomegranate extract and its metabolite urolithin-A in a colitis rat model and the effect of colon inflammation on phenolic metabolism. J. Nutr. Biochem. 2010, 21, 717-725. [CrossRef]

87. Ouachrif, A.; Khalki, H.; Chaib, S.; Mountassir, M.; Aboufatima, R.; Farouk, L.; Benharraf, A.; Chait, A. Comparative study of the anti-inflammatory and antinociceptive effects of two varieties of Punica granatum. Pharm. Biol. 2012, 50, 429-438. [CrossRef] [PubMed]

88. Park, S.; Seok, J.K.; Kwak, J.Y.; Suh, H.J.; Kim, Y.M.; Boo, Y.C. Anti-Inflammatory Effects of Pomegranate Peel Extract in THP-1 Cells Exposed to Particulate Matter PM10. Evid. Based Complement. Altern. Med. 2016, 2016, 1-11. [CrossRef]

89. Xu, J.; Zhao, Y.; Aisa, H.A. Anti-inflammatory effect of pomegranate flower in lipopolysaccharide (LPS)-stimulated RAW264.7 macrophages. Pharm. Biol. 2017, 55, 2095-2101. [CrossRef] [PubMed]

90. Kim, H.; Banerjee, N.; Ivanov, I.; Pfent, C.M.; Prudhomme, K.R.; Bisson, W.H.; Dashwood, R.H.; Talcott, S.T.; Mertens-Talcott, S.U. Comparison of anti-inflammatory mechanisms of mango (Mangifera indica L.) and pomegranate (Punica granatum L.) in a preclinical model of colitis. Mol. Nutr. Food Res. 2016, 60, 1912-1923. [CrossRef] [PubMed]

91. Gonzalez-Trujano, M.E.; Pellicer, F.; Mena, P.; Moreno, D.A.; Garcia-Viguera, C. Antinociceptive and anti-inflammatory activities of a pomegranate (Punica granatum L.) extract rich in ellagitannins. Int. J. Food Sci. Nutr. 2015, 66, 395-399. [CrossRef]

92. Mo, J.; Panichayupakaranant, P.; Kaewnopparat, N.; Songkro, S.; Reanmongkol, W. Topical anti-inflammatory potential of standardized pomegranate rind extract and ellagic acid in contact dermatitis. Phytother. Res. 2014, 28, 629-632. [CrossRef]

93. Ruffo, M.; Parisi, O.I.; Scrivano, L.; Restuccia, D.; Amone, F.; Sinicropi, M.S.; Malivindi, R.; Aiello, G.; Puoci, F. Role of Calabrian Black Rice in Metabolic Syndrome: In vitro Evaluation of Oryza sativa L. Indica Biological Properties. Curr. Nutr. Food Sci. 2018, 14, 121-127. [CrossRef]

94. Cheng, J.T.; Liu, I.M. Stimulatory effect of caffeic acid on alpha1A-adrenoceptors to increase glucose uptake into cultured C2C12 cells. Naunyn Schmiedebergs Arch. Pharmacol. 2000, 362, 122-127. [CrossRef]

95. Li, Y.; Wen, S.; Kota, B.P.; Peng, G.; Li, G.Q.; Yamahara, J.; Roufogalis, B.D. Punica granatum flower extract, a potent alpha-glucosidase inhibitor, improves postprandial hyperglycemia in Zucker diabetic fatty rats. J. Ethnopharmacol. 2005, 99, 239-244. [CrossRef]

96. Huang, T.H.W.; Peng, G.; Kota, B.P.; Li, G.Q.; Yamahara, J.; Roufogalis, B.D.; Li, Y.H. Anti-diabetic action of Punica granatum flower extract: Activation of PPAR-gamma and identification of an active component. Toxicol. Appl. Pharmacol. 2005, 207, 160-169. [CrossRef]

97. McFarlin, B.K.; Strohacker, K.A.; Kueht, M.L. Pomegranate seed oil consumption during a period of high-fat feeding reduces weight gain and reduces type 2 diabetes risk in CD-1 mice. Br. J. Nutr. 2009, 102, 54-59. [CrossRef] [PubMed]

98. Parmar, H.S.; Kar, A. Medicinal values of fruit peels from Citrus sinensis, Punica granatum, and Musa paradisiaca with respect to alterations in tissue lipid peroxidation and serum concentration of glucose, insulin, and thyroid hormones. J. Med. Food 2008, 11, 376-381. [CrossRef] [PubMed]

99. Makino-Wakagi, Y.; Yoshimura, Y.; Uzawa, Y.; Zaima, N.; Moriyama, T.; Kawamura, Y. Ellagic acid in pomegranate suppresses resistin secretion by a novel regulatory mechanism involving the degradation of intracellular resistin protein in adipocytes. Biochem. Biophys. Res. Commun. 2012, 417, 880-885. [CrossRef] [PubMed] 
100. Cambay, Z.; Baydas, G.; Tuzcu, M.; Bal, R. Pomegranate (Punica granatum L.) flower improves learning and memory performances impaired by diabetes mellitus in rats. Acta Physiol. Hung. 2011, 98, 409-420. [CrossRef]

101. Faghihimani, Z.; Mirmiran, P.; Sohrab, G.; Iraj, B.; Faghihimani, E. Effects of Pomegranate Seed Oil on Metabolic State of Patients with Type 2 Diabetes Mellitus. Int. J. Prev. Med. 2016, 7, 124.

102. Tang, D.; Liu, L.; Ajiakber, D.; Ye, J.; Xu, J.; Xin, X.; Aisa, H.A. Anti-diabetic Effect of Punica granatum Flower Polyphenols Extract in Type 2 Diabetic Rats: Activation of Akt/GSK-3beta and Inhibition of IRE1alpha-XBP1 Pathways. Front. Endocrinol. 2018, 9, 586. [CrossRef]

103. Gharib, E.; Montasser Kouhsari, S. Study of the Antidiabetic Activity of Punica granatum L. Fruits Aqueous Extract on the Alloxan-Diabetic Wistar Rats. Iran. J. Pharm. Res. 2019, 18, 358-368.

104. Mustafa, S.M.; Chua, L.S.; El-Enshasy, H.A.; Abd Majid, F.A.; Hanapia, S.Z. Kinetic profile and anti-diabetic potential of fermented Punica granatum juice using Lactobacillus casei. Process. Biochem. 2020, 92, 224-231. [CrossRef]

105. Banihani, S.A.; Shuaibu, S.M.; Al-Husein, B.A.; Makahleh, S.S. Fresh Pomegranate Juice Decreases Fasting Serum Erythropoietin in Patients with Type 2 Diabetes. Int. J. Food Sci. 2019, 2019, 1269341. [CrossRef]

106. Davidson, P.M.; Branen, A.L. Food Antimicrobials-An Introduction. In Antimicrobials in Food; Davidson, P.M., Sofos, J.M., Branen, A.L., Eds.; CRC Press: Boca Raton, FL, USA, 2005.

107. Fawole, O.A.; Makunga, N.P.; Opara, U.L. Antibacterial, antioxidant and tyrosinase-inhibition activities of pomegranate fruit peel methanolic extract. BMC Complement. Altern. Med. 2012, 12, 200. [CrossRef]

108. Naz, S.; Siddiqi, R.; Ahmad, S.; Rasool, S.A.; Sayeed, S.A. Antibacterial activity directed isolation of compounds from Punica granatum. J. Food Sci. 2007, 72, M341-M345. [CrossRef] [PubMed]

109. Vasconcelos, L.C.; Sampaio, M.C.; Sampaio, F.C.; Higino, J.S. Use of Punica granatum as an antifungal agent against candidosis associated with denture stomatitis. Mycoses 2003, 46, 192-196. [CrossRef] [PubMed]

110. Al-Zoreky, N.S. Antimicrobial activity of pomegranate (Punica granatum L.) fruit peels. Int. J. Food Microbiol. 2009, 134, 244-248. [CrossRef] [PubMed]

111. Wafa, B.A.; Makni, M.; Ammar, S.; Khannous, L.; Hassana, A.B.; Bouaziz, M.; Es-Safi, N.E.; Gdoura, R. Antimicrobial effect of the Tunisian Nana variety Punica granatum L. extracts against Salmonella enterica (serovars Kentucky and Enteritidis) isolated from chicken meat and phenolic composition of its peel extract. Int. J. Food Microbiol. 2017, 241, 123-131. [CrossRef] [PubMed]

112. Visnjevec, A.M.; Ota, A.; Skrt, M.; Butinar, B.; Mozina, S.S.; Cimerman, N.G.; Necemer, M.; Arbeiter, A.B.; Hladnik, M.; Krapac, M.; et al. Genetic, Biochemical, Nutritional and Antimicrobial Characteristics of Pomegranate (Punica granatum L.)Grown in Istria. Food Technol. Biotechnol. 2017, 55, 151-163.

113. Devanesan, S.; AlSalhi, M.S.; Balaji, R.V.; Ranjitsingh, A.J.A.; Ahamed, A.; Alfuraydi, A.A.; AlQahtani, F.Y.; Aleanizy, F.S.; Othman, A.H. Antimicrobial and Cytotoxicity Effects of Synthesized Silver Nanoparticles from Punica granatum Peel Extract. Nanoscale Res. Lett. 2018, 13, 315. [CrossRef]

114. Esmaillzadeh, A.; Azadbakht, L. Food intake patterns may explain the high prevalence of cardiovascular risk factors among Iranian women. J. Nutr. 2008, 138, 1469-1475. [CrossRef]

115. Zirpoli, H.; Caputo, M.; Carraturo, A.; Torino, G.; Fazio, A.; Attya, M.; Rastrelli, L.; Tecce, M.F. Selective action of human sera differing in fatty acids and cholesterol content on in vitro gene expression. J. Cell Biochem. 2012, 113, 815-823. [CrossRef]

116. Heinecke, J.W. Lipoprotein oxidation in cardiovascular disease: Chief culprit or innocent bystander? J. Exp. Med. 2006, 203, 813-816. [CrossRef]

117. Khateeb, J.; Gantman, A.; Kreitenberg, A.J.; Aviram, M.; Fuhrman, B. Paraoxonase 1 (PON1) expression in hepatocytes is upregulated by pomegranate polyphenols: A role for PPAR-gamma pathway. Atherosclerosis 2010, 208, 119-125. [CrossRef]

118. Riaz, A.; Khan, R.A. Anticoagulant, antiplatelet and antianemic effects of Punica granatum (pomegranate) juice in rabbits. Blood Coagul. Fibrinolysis 2016, 27, 287-293. [CrossRef]

119. Razani, Z.; Dastani, M.; Kazerani, H.R. Cardioprotective Effects of Pomegranate (Punica granatum) Juice in Patients with Ischemic Heart Disease. Phytother. Res. 2017, 31, 1731-1738. [CrossRef] 
120. Patel, I.B.; Atar, M.A.; Ali, S.A. Punica granatum Peel Extract Ameliorates Doxorubicin Induced Cardiotoxicity. Anal. Chem. Lett. 2019, 9, 835-844. [CrossRef]

121. Boldaji, R.B.; Akhlaghi, M.; Sagheb, M.M.; Esmaeilinezhad, Z. Pomegranate juice improves cardiometabolic risk factors, biomarkers of oxidative stress and inflammation in hemodialysis patients: A randomized crossover trial. J. Sci. Food Agric. 2019. [CrossRef] [PubMed]

122. Sohrab, G.; Roshan, H.; Ebrahimof, S.; Nikpayam, O.; Sotoudeh, G.; Siasi, F. Effects of pomegranate juice consumption on blood pressure and lipid profile in patients with type 2 diabetes: A single-blind randomized clinical trial. Clin. Nutr. Espen. 2019, 29, 30-35. [CrossRef] [PubMed]

123. Caruso, A.; Ceramella, J.; Iacopetta, D.; Saturnino, C.; Mauro, M.V.; Bruno, R.; Aquaro, S.; Sinicropi, M.S. Carbazole Derivatives as Antiviral Agents: An Overview. Molecules 2019, 24, 1912. [CrossRef]

124. Sundararajan, A.; Ganapathy, R.; Huan, L.; Dunlap, J.R.; Webby, R.J.; Kotwal, G.J.; Sangster, M.Y. Influenza virus variation in susceptibility to inactivation by pomegranate polyphenols is determined by envelope glycoproteins. Antivir. Res. 2010, 88, 1-9. [CrossRef]

125. Haidari, M.; Ali, M.; Ward Casscells, S.; Madjid, M. Pomegranate (Punica granatum) purified polyphenol extract inhibits influenza virus and has a synergistic effect with oseltamivir. Phytomedicine 2009, 16, 1127-1136. [CrossRef]

126. Yang, Y.; Xiu, J.; Zhang, L.; Qin, C.; Liu, J. Antiviral activity of punicalagin toward human enterovirus 71 in vitro and in vivo. Phytomedicine 2012, 20,67-70. [CrossRef]

127. Reddy, B.U.; Mullick, R.; Kumar, A.; Sudha, G.; Srinivasan, N.; Das, S. Small molecule inhibitors of HCV replication from pomegranate. Sci. Rep. 2014, 4, 5411. [CrossRef]

128. Moradi, M.; Karimi, A.; Alidadi, S.; Saedi-Marghmaleki, M.; Salehian, M. In vitro Anti-adenovirus activity of pomegranate (Punica granatum L.) peel extract. Adv. Herb. Med. 2016, 2, 1-8.

129. Houston, D.M.J.; Bugert, J.J.; Denyer, S.P.; Heard, C.M. Correction: Potentiated virucidal activity of pomegranate rind extract (PRE) and punicalagin against Herpes simplex virus (HSV) when co-administered with zinc (II) ions, and antiviral activity of PRE against HSV and aciclovir-resistant HSV. PLoS ONE 2017, 12, e0188609. [CrossRef] [PubMed]

130. Arunkumar, J.; Rajarajan, S. Study on antiviral activities, drug-likeness and molecular docking of bioactive compounds of Punica granatum L. to Herpes simplex virus-2 (HSV-2). Microb. Pathog. 2018, 118, 301-309. [CrossRef] [PubMed]

131. Rehman, M.T.; AlAjmi, M.F.; Hussain, A. Natural Compounds as Inhibitors of SARS-CoV-2 Main Protease (3CLpro): A Molecular Docking and Simulation Approach to Combat COVID-19. Chem. Rxiv. 2020. [CrossRef]

132. Vardhan, S.; Sahoo, S.K. Searching inhibitors for three important proteins of COVID-19 through molecular docking studies. arXiv 2020, arXiv:2006.1667.

133. Khalifa, I.; Zhu, W.; Nafie, M.S.; Dutta, K.; Li, C. Anti-COVID-19 Effects of Ten Structurally Different Hydrolysable Tannins through Binding with the Catalytic-Closed Sites of COVID-19 Main Protease: An In-Silico Approach. Preprints 2020. [CrossRef]

134. Nettore, I.C.; Rocca, C.; Mancino, G.; Albano, L.; Amelio, D.; Grande, F.; Puoci, F.; Pasqua, T.; Desiderio, S.; Mazza, R.; et al. Quercetin and its derivative Q2 modulate chromatin dynamics in adipogenesis and Q2 prevents obesity and metabolic disorders in rats. J. Nutr. Biochem. 2019, 69, 151-162. [CrossRef]

135. Mackay, J.; Mensah, G.; Mendis, S.; Greenland, K. The Atlas of Heart Disease and Stroke; World Health Organization, Ed.; World Health Organization in collaboration with the USA Centers for Disease Control and Prevention; World Health Organization: Geneva, Switzerland, 2004.

136. Cerda, B.; Ceron, J.J.; Tomas-Barberan, F.A.; Espin, J.C. Repeated oral administration of high doses of the pomegranate ellagitannin punicalagin to rats for 37 days is not toxic. J. Agric. Food. Chem. 2003, 51, 3493-3501. [CrossRef]

137. Lei, F.; Zhang, X.N.; Wang, W.; Xing, D.M.; Xie, W.D.; Su, H.; Du, L.J. Evidence of anti-obesity effects of the pomegranate leaf extract in high-fat diet induced obese mice. Int. J. Obes. 2007, 31, 1023-1029. [CrossRef]

138. Trichur Khabeer, S.; Prashant, A.; Haravey Krishnan, M. Dietary fatty acids from pomegranate seeds (Punica granatum) inhibit adipogenesis and impact the expression of the obesity-associated mRNA transcripts in human adipose-derived mesenchymal stem cells. J. Food Biochem. 2019, 43, e12739. [CrossRef] 
139. Seeram, N.P.; Henning, S.M.; Zhang, Y.; Suchard, M.; Li, Z.; Heber, D. Pomegranate juice ellagitannin metabolites are present in human plasma and some persist in urine for up to 48 hours. J. Nutr. 2006, 136, 2481-2485. [CrossRef] [PubMed]

140. Bialonska, D.; Kasimsetty, S.G.; Schrader, K.K.; Ferreira, D. The effect of pomegranate (Punica granatum L.) byproducts and ellagitannins on the growth of human gut bacteria. J. Agric. Food. Chem. 2009, 57, 8344-8349. [CrossRef]

141. Chaves, F.M.; Baptista, I.L.; Simabuco, F.M.; Quaresma, P.G.F.; Pena, F.L.; Bezerra, R.M.N.; Pauli, J.R.; da Cunha, D.T.; Campos-Ferraz, P.L.; Antunes, A.E.C. High-intensity-exercise-induced intestinal damage is protected by fermented milk supplemented with whey protein, probiotic and pomegranate (Punica granatum L.). Br. J. Nutr. 2018, 119, 896-909. [CrossRef] [PubMed]

142. George, N.S.; Cheung, L.M.; Luthria, D.L.; Santin, M.; Dawson, H.D.; Bhagwat, A.A.; Smith, A.D. Pomegranate peel extract alters the microbiome in mice and dysbiosis caused by Citrobacter rodentium infection. Food Sci. Nutr. 2019, 7, 2565-2576. [PubMed]

143. Smith, A.D.; George, N.S.; Cheung, L.; Bhagavathy, G.V.; Luthria, D.L.; John, K.M.; Bhagwat, A.A. Pomegranate peel extract reduced colonic damage and bacterial translocation in a mouse model of infectious colitis induced by Citrobacter rodentium. Nutr. Res. 2020, 73, 27-37. [CrossRef]

144. Turk, G.; Sonmez, M.; Aydin, M.; Yuce, A.; Gur, S.; Yuksel, M.; Aksu, E.H.; Aksoy, H. Effects of pomegranate juice consumption on sperm quality, spermatogenic cell density, antioxidant activity and testosterone level in male rats. Clin. Nutr. 2008, 27, 289-296. [CrossRef]

145. Turk, G.; Sonmez, M.; Ceribasi, A.O.; Yuce, A.; Atessahin, A. Attenuation of cyclosporine A-induced testicular and spermatozoal damages associated with oxidative stress by ellagic acid. Int. Immunopharmacol. 2010, 10, 177-182. [CrossRef]

146. Forest, C.P.; Padma-Nathan, H.; Liker, H.R. Efficacy and safety of pomegranate juice on improvement of erectile dysfunction in male patients with mild to moderate erectile dysfunction: A randomized, placebo-controlled, double-blind, crossover study. Int. J. Impot. Res. 2007, 19, 564-567. [CrossRef]

147. Qnais, E.Y.; Elokda, A.S.; Abu Ghalyun, Y.Y.; Abdulla, F.A. Antidiarrheal activity of the aqueous extract of Punica granatum (pomegranate) peels. Pharm. Biol. 2007, 45, 715-720. [CrossRef]

148. Olapour, S.; Mousavi, E.; Sheikhzade, M.; Hoseininezhad, O.; Najafzadeh, H. Evaluation antidiarrheal effects of pomegranate peel extract. J. Iran. Chem. Soc. 2009, 6, 115-143.

149. Zhao, S.S.; Ma, D.X.; Zhu, Y.; Zhao, J.H.; Zhang, Y.; Chen, J.Q.; Sheng, Z.L. Antidiarrheal effect of bioactivity-guided fractions and bioactive components of pomegranate (Punica granatum L.) peels. Neurogastroenterol. Motil. 2018, 30, e13364. [CrossRef] [PubMed]

150. Dumitrescu, A.L. Influence of periodontal disease on cardiovascular diseases. Rom. J. Intern. Med. 2005, 43, 9-21. [PubMed]

151. DiSilvestro, R.A.; DiSilvestro, D.J.; DiSilvestro, D.J. Pomegranate Extract Mouth Rinsing Effects on Saliva Measures Relevant to Gingivitis Risk. Phytother. Res. 2009, 23, 1123-1127. [CrossRef]

152. Sastravaha, G.; Gassmann, G.; Sangtherapitikul, P.; Grimm, W.D. Adjunctive periodontal treatment with Centella asiatica and Punica granatum extracts in supportive periodontal therapy. J. Int. Acad. Periodontol. 2005, 7, 70-79. [PubMed]

153. Al-Wazni, W.S.; Hadi, B.S. Antivirulence effects of pomegranate peel extracts on most common urinary tract infection pathogens in pregnant women. J. Contemp. Med. Sci. 2015, 1, 7-12. [CrossRef]

154. Manouchehrian, M.; Shakiba, M.; Shariat, M.; Lotfi, M.H.; Kamalinejad, M.; Babaeian, M. The Effect of Pomegranate Paste on Neonatal Jaundice Incidence: A Clinical Trial in Women during Pregnancy. Int. J. Clin. Med. 2017, 8, 144-151. [CrossRef]

155. Finn-Sell, S.L.; Cottrell, E.C.; Greenwood, S.L.; Dilworth, M.R.; Cowley, E.J.; Sibley, C.P.; Wareing, M. Pomegranate Juice Supplementation Alters Utero-Placental Vascular Function and Fetal Growth in the eNOS-/- Mouse Model of Fetal Growth Restriction. Front. Physiol. 2018, 9, 1145. [CrossRef]

156. Henning, S.M.; Wallenstein, M.B.; Weigel, N.; Johnson, C.; Yang, J.; Lee, R.; Korn, M.; Scala, M.; Stevenson, K.D.; Ben-Nissan, D.; et al. Appearance of Ellagic Acid Metabolites from Pomegranate Juice in Breast Milk: A Case Report. Ann. Clin. Case Rep. 2019, 4, 1738. 
157. Heneka, M.T.; Carson, M.J.; El Khoury, J.; Landreth, G.E.; Brosseron, F.; Feinstein, D.L.; Jacobs, A.H.; Wyss-Coray, T.; Vitorica, J.; Ransohoff, R.M.; et al. Neuroinflammation in Alzheimer's disease. Lancet Neurol. 2015, 14, 388-405. [CrossRef]

158. DaSilva, N.A.; Nahar, P.P.; Ma, H.; Eid, A.; Wei, Z.; Meschwitz, S.; Zawia, N.H.; Slitt, A.L.; Seeram, N.P. Pomegranate ellagitannin-gut microbial-derived metabolites, urolithins, inhibit neuroinflammation in vitro. Nutr. Neurosci. 2019, 22, 185-195. [CrossRef]

159. Velagapudi, R.; Lepiarz, I.; El-Bakoush, A.; Katola, F.O.; Bhatia, H.; Fiebich, B.L.; Olajide, O.A. Induction of Autophagy and Activation of SIRT-1 Deacetylation Mechanisms Mediate Neuroprotection by the Pomegranate Metabolite Urolithin A in BV2 Microglia and Differentiated 3D Human Neural Progenitor Cells. Mol. Nutr. Food Res. 2019, 63, e1801237. [CrossRef] [PubMed]

160. Casedas, G.; Les, F.; Choya-Foces, C.; Hugo, M.; Lopez, V. The Metabolite Urolithin-A Ameliorates Oxidative Stress in Neuro-2a Cells, Becoming a Potential Neuroprotective Agent. Antioxidants 2020, 9, 177. [CrossRef] [PubMed]

161. Kujawska, M.; Jourdes, M.; Kurpik, M.; Szulc, M.; Szaefer, H.; Chmielarz, P.; Kreiner, G.; Krajka-Kuzniak, V.; Mikolajczak, P.L.; Teissedre, P.L.; et al. Neuroprotective Effects of Pomegranate Juice against Parkinson's Disease and Presence of Ellagitannins-Derived Metabolite-Urolithin A-In the Brain. Int. J. Mol. Sci. 2020, 21, 202. [CrossRef] [PubMed]

162. Siddarth, P.; Li, Z.P.; Miller, K.J.; Ercoli, L.M.; Merril, D.A.; Henning, S.M.; Heber, D.; Small, G.W. Randomized placebo-controlled study of the memory effects of pomegranate juice in middle-aged and older adults. Am. J. Clin. Nutr. 2020, 111, 170-177. [CrossRef]

163. Vidal, A.; Fallarero, A.; Pena, B.R.; Medina, M.E.; Gra, B.; Rivera, F.; Gutierrez, Y.; Vuorela, P.M. Studies on the toxicity of Punica granatum L. (Punicaceae) whole fruit extracts. J. Ethnopharmacol. 2003, 89, 295-300. [CrossRef]

164. Heber, D.; Seeram, N.P.; Wyatt, H.; Henning, S.M.; Zhang, Y.; Ogden, L.G.; Dreher, M.; Hill, J.O. Safety and antioxidant activity of a pomegranate ellagitannin-enriched polyphenol dietary supplement in overweight individuals with increased waist size. J. Agric. Food Chem. 2007, 55, 10050-10054. [CrossRef] [PubMed]

165. Aviram, M.; Rosenblat, M.; Gaitini, D.; Nitecki, S.; Hoffman, A.; Dornfeld, L.; Volkova, N.; Presser, D.; Attias, J.; Liker, H.; et al. Pomegranate juice consumption for 3 years by patients with carotid artery stenosis reduces common carotid intima-media thickness, blood pressure and LDL oxidation. Clin. Nutr. 2004, 23, 423-433. [CrossRef]

166. Chimento, A.; Sirianni, R.; Saturnino, C.; Caruso, A.; Sinicropi, M.S.; Pezzi, V. Resveratrol and Its Analogs as Antitumoral Agents for Breast Cancer Treatment. Mini Rev. Med. Chem. 2016, 16, 699-709. [CrossRef]

167. Iacopetta, D.; Rosano, C.; Puoci, F.; Parisi, O.I.; Saturnino, C.; Caruso, A.; Longo, P.; Ceramella, J.; Malzert-Freon, A.; Dallemagne, P.; et al. Multifaceted properties of 1,4-dimethylcarbazoles: Focus on trimethoxybenzamide and trimethoxyphenylurea derivatives as novel human topoisomerase II inhibitors. Eur. J. Pharm. Sci. 2017, 96, 263-272. [CrossRef]

168. Sala, M.; Chimento, A.; Saturnino, C.; Gomez-Monterrey, I.M.; Musella, S.; Bertamino, A.; Milite, C.; Sinicropi, M.S.; Caruso, A.; Sirianni, R.; et al. Synthesis and cytotoxic activity evaluation of 2,3-thiazolidin-4-one derivatives on human breast cancer cell lines. Bioorg. Med. Chem. Lett. 2013, 23, 4990-4995. [CrossRef]

169. Tundis, R.; Iacopetta, D.; Sinicropi, M.S.; Bonesi, M.; Leporini, M.; Passalacqua, N.G.; Ceramella, J.; Menichini, F.; Loizzo, M.R. Assessment of antioxidant, antitumor and pro-apoptotic effects of Salvia fruticosa Mill. subsp. thomasii (Lacaita) Brullo, Guglielmo, Pavone \& Terrasi (Lamiaceae). Food Chem. Toxicol. 2017, 106, 155-164. [PubMed]

170. Ceramella, J.; Loizzo, M.R.; Iacopetta, D.; Bonesi, M.; Sicari, V.; Pellicano, T.M.; Saturnino, C.; Malzert-Freon, A.; Tundis, R.; Sinicropi, M.S. Anchusa azurea Mill. (Boraginaceae) aerial parts methanol extract interfering with cytoskeleton organization induces programmed cancer cells death. Food Funct. 2019, 10, 4280-4290. [CrossRef] [PubMed]

171. Francomano, F.; Caruso, A.; Barbarossa, A.; Fazio, A.; La Torre, C.; Ceramella, J.; Mallamaci, R.; Saturnino, C.; Iacopetta, D.; Sinicropi, M.S. $\beta$-Caryophyllene: A Sesquiterpene with Countless Biological Properties. Appl. Sci. 2019, 9, 5420. [CrossRef] 
172. Khomich, L.M.; Perova, I.B.; Eller, K.I. Pomegranate juice nutritional profile. Vopr. Pitan. 2019, 88, 80-92. [PubMed]

173. Bar-Ya'akov, I.; Tian, L.; Amir, R.; Holland, D. Primary Metabolites, Anthocyanins, and Hydrolyzable Tannins in the Pomegranate Fruit. Front. Plant Sci. 2019, 10, 620. [CrossRef] [PubMed]

174. Vucic, V.; Grabez, M.; Trchounian, A.; Arsic, A. Composition and Potential Health Benefits of Pomegranate: A Review. Curr. Pharm. Des. 2019, 25, 1817-1827. [CrossRef] [PubMed]

175. Viswanath, M.; Sridevi, P.; Bhagavan, B.V.K.; Ravindra Kumar, K.; Subbaramamma, P. Toxicological, Pharmacological and Cellular properties of Pomegranate (Punica granatum L.): A Review. J. Pharmacogn. Phytochem. 2019, 8, 172-176.

176. Natalello, A.; Hervas, G.; Toral, P.G.; Luciano, G.; Valenti, B.; Mendoza, A.G.; Pauselli, M.; Priolo, A.; Frutos, P. Bioactive compounds from pomegranate by-products increase the in vitro ruminal accumulation of potentially health promoting fatty acids. Anim. Feed Sci. Technol. 2020, 259, 114355. [CrossRef]

177. Prakash, C.V.S.; Prakash, I. Bioactive Chemical Constituents from Pomegranate (Punica Granatum) Juice, Seed and Peel-A Review. Int. J. Res. Chem. Environ. 2011, 1, 1-18.

178. Sateriale, D.; Facchiano, S.; Colicchio, R.; Pagliuca, C.; Varricchio, E.; Paolucci, M.; Volpe, M.G.; Salvatore, P.; Pagliarulo, C. In vitro Synergy of Polyphenolic Extracts from Honey, Myrtle and Pomegranate Against Oral Pathogens, S. mutans and R. dentocariosa. Front. Microbiol. 2020, 11, 1465. [CrossRef]

(C) 2020 by the authors. Licensee MDPI, Basel, Switzerland. This article is an open access article distributed under the terms and conditions of the Creative Commons Attribution (CC BY) license (http://creativecommons.org/licenses/by/4.0/). 